\title{
Three-dimensional joint inversion of traveltime and gravity data across the Chicxulub impact crater
}

\author{
P. M. Vermeesch, ${ }^{1,2}$ J. V. Morgan, ${ }^{3}$ G. L. Christeson, ${ }^{1}$ P. J. Barton, ${ }^{4}$ and A. Surendra ${ }^{4}$
}

Received 30 April 2008; revised 28 October 2008; accepted 17 December 2008; published 18 February 2009.

[1] In 2005 an extensive new seismic refraction data set was acquired over the central part of the Chicxulub impact crater, allowing us to image its structure with much better resolution than before. However, models derived from traveltime data are limited by the available ray coverage and the nonuniqueness that is inherent to all geophysical methods. Therefore, many different models can fit the data equally well. To address these issues, we have developed a new method to simultaneously invert traveltime and gravity data to obtain an integrated model. To convert velocity to density, we use a linear relationship derived from measurements on core from the Chicxulub impact basin, thus providing a reliable conversion equation that is typical for lithologies of the central part of this crater. Prior to utilizing the inversion on the observed data, we have run a suite of tests to establish the optimum weighting between traveltime and gravity constraints, using a synthetic model of central crater structure and the real experimental geometry. These synthetic tests indicate which inversion parameters lead to the best recovery of subsurface structure, as well as which parts of the model are well resolved. We applied the method to all existing gravity data and to seismic refraction data acquired in 1996 and the new, higher-resolution seismic refraction data acquired in 2005. We favor the traveltime model wherever we have sufficient ray coverage and the joint model where we have no ray coverage.

Citation: Vermeesch, P. M., J. V. Morgan, G. L. Christeson, P. J. Barton, and A. Surendra (2009), Three-dimensional joint inversion of traveltime and gravity data across the Chicxulub impact crater, J. Geophys. Res., 114, B02105, doi:10.1029/2008JB005776.

\section{Introduction}

[2] In 1996 a seismic reflection and refraction experiment across the Chicxulub impact crater in Yucatán (Mexico) shed new light on the structure and formation of large impact craters [e.g., Christeson et al., 1999, 2001; Morgan et al., 2000, 2002a]. A second seismic experiment carried out in 2005 improved the resolution of these seismic models significantly and allowed better constraints on the crater asymmetries [Gulick et al., 2008] and the central uplift [Vermeesch and Morgan, 2008]. Numerical models for the formation of large complex impact craters and multiring basins all show an upward movement within the center of the crater during collapse [e.g., Grieve et al., 1981; Collins et al., 2002; Wünnemann et al., 2005; Senft and Stewart, 2007]. When excavation has ceased, the uplifted rim collapses inward and downward to form a terrace zone, and the uplifted central zone collapses downward and outward to form a peak

\footnotetext{
${ }^{1}$ Institute for Geophysics, University of Texas at Austin, Austin, Texas, USA.

${ }^{2}$ Now at School of Ocean and Earth Sciences, National Oceanography Centre, Southampton University, Southampton, UK.

${ }^{3}$ Department of Earth Science and Engineering, Imperial College London, London, UK.

${ }^{4}$ Department of Earth Sciences, University of Cambridge, Cambridge, UK.

Copyright 2009 by the American Geophysical Union. 0148-0227/09/2008JB005776\$09.00
}

ring [e.g., Collins et al., 2002]. The precise kinematics and dynamics of large impact crater formation are still relatively poorly understood. The main debate is on the target strength and mechanism of weakening of crustal and mantle rocks during excavation and subsequent collapse stages. Numerical modeling indicates that the target strength has a strong influence on final crater shape [Wünnemann et al., 2005; Bray et al., 2007; Stewart and Senft, 2007], and therefore detailed knowledge of the geometry of large impact craters, and stratigraphic uplift in particular, is crucial to constraining the kinematics of large crater formation.

[3] The Chicxulub impact crater is by far the youngest and most pristine of only three identified terrestrial impact craters larger than $\sim 150 \mathrm{~km}$, i.e., the diameter at which the transition from large complex craters to multiring basins (defined as having at least two asymmetric scarps [Morgan et al., 2002b]) is expected to occur [e.g., Melosh, 1989]. Because the collapsed impact crater was buried slowly on a stable carbonate platform after the impact $65 \mathrm{Ma}$ ago, it is very well preserved and ideal for investigation by geophysical methods and drilling. The main feature of the central part of the crater is an anomalous zone that has a high seismic velocity [Morgan et al., 2000], a high density [Hildebrand et al., 1998], and a strong magnetic signature [Pilkington and Hildebrand, 2000], interpreted as uplifted strata and widely referred to as the central uplift. Contradicting interpretations have been made regarding the shape of the top of this feature and its lateral and vertical extent 
(for a discussion on the shape of the central uplift, see Vermeesch and Morgan [2004]). The potential field model shows a more or less flat top at $\sim 2 \mathrm{~km}$ depth and an increase with depth of the width of the central uplift [Hildebrand et al., 1998], while the seismic refraction model shows a concaveupward or cup-shaped top at $\sim 3 \mathrm{~km}$ depth. The width of the central uplift decreases with depth in the upper $\sim 3 \mathrm{~km}$ [Morgan et al., 2000, 2002a].

[4] Both seismic tomographic and gravity methods are limited by the nonuniqueness that is inherent to all geophysical methods. Therefore a range of velocity and density models can fit the data equally well. Resolution of velocity models derived from seismic refraction data is also limited by the available ray coverage. One way to address these issues is to combine traveltime and gravity data sets to obtain an integrated velocity/density model. This allows exploration of the model space that is consistent with both data sets and is likely to be more effective than modeling both data sets separately by decreasing the extent of some of the ambiguities inherent to individual data sets [Jegen et al., 2006]. The most common way of integrating gravity data in a tomographic inversion is either by the a posteriori validation of the recovered velocity model by assuming a certain relationship between velocity and density, or by providing some a priori constraints that can be incorporated in the starting model. These methods suffer from subjectivity and will not easily discover all possible models that fit the data equally well.

[5] A more efficient way of integrating different independent data sets is called cooperative inversion [Lines et al., 1988]. There are many possible approaches which allow inversion of several independent data sets. Joint inversion involves the simultaneous inversion of two weighted data sets. Such schemes were developed by Lees and Vandecar [1991], Nielsen and Jacobsen [2000], Afnimar et al. [2002], and Roy et al. [2005]. The biggest challenge in this type of cooperative inversion is the weighting of the two different data sets in the inversion. This is not an issue in sequential inversions, where the inversion results of one data set provide the input or starting model for the inversion of the second data set [e.g., Lines et al., 1988; Tondi et al., 2000; Wang et al., 2004; Tikhotsky and Achauer, 2008]. The parameterization of cooperative inversions can be classified in three categories, which were termed U, S, and C by Golizdra [1980]: (1) coupling between density and velocity and the same parameterization for both density and velocity models (U for unified), (2) no coupling between density and velocity and independent parameterization (S for separate), and (3) a mixture of the above ( $\mathrm{C}$ for compromise).

[6] To better constrain the central uplift of the Chicxulub crater, Vermeesch and Morgan [2008] used gravity data as well as the 1996 and higher-resolution 2005 seismic refraction data to derive a velocity and density model that fits both data sets. This paper explains the technical aspects of the joint inversion method that was developed by Vermeesch [2006] by introducing gravity into the First-Arrival Seismic Tomography (FAST) method of Zelt and Barton [1998] and Zelt et al. [2006] using the unified approach for the model parameterization. The performance of the joint inversion is optimized using test results from a synthetic model of central crater structure, by examining model recovery for a range of inversion parameters, including weighting between traveltime and gravity constraints. The uncertainties of this velocity/density model are explored in comparison with the uncertainties of a velocity model derived from traveltime inversion using the FAST method.

[7] A major uncertainty of joint inversions lies in the relationship between density and velocity. Joint inversions of gravity and seismic data that use the unified approach often use empirically derived equations based on both laboratory experiments and well log data (e.g., the NafeDrake relationship of Ludwig et al. [1970]). In contrast, this paper uses a linear velocity-density relationship derived from measurements on core from the Chicxulub impact basin, thus providing a more reliable velocity-density conversion that is typical for the lithologies encountered at the center of the Chicxulub crater. Other model uncertainties and nonuniqueness result from traveltime and gravity errors, sparse data coverage, model parameterizations, and the choice of additional constraints and weighting parameters. A comparison between the results using the 1996 and 2005 refraction data shows the importance of acquiring data on a densely spaced grid.

\section{Data}

\subsection{Seismic Refraction Data}

[8] We use a combination of seismic refraction data acquired during the 1996 British Institutions Reflection Profiling Syndicate (BIRPS) Chicxulub experiment [Morgan et al., 2000, 2002a; Christeson et al., 1999, 2001] and the 2005 Chicxulub experiment (Figure 1a). Both were combined onshore-offshore experiments. The 2005 seismic experiment included 30,200 air gun shots recorded on a $6 \mathrm{~km}$ long, 480 channel hydrophone streamer and on 48 ocean bottom seismometers (OBSs) in two deployments. It also included 6360 air gun shots not recorded on the streamer. The 82 land seismometers recorded all 36,560 air gun shots. Cruise EW0501 on the R/V Maurice Ewing used a source that consisted of 20 air guns with a total volume of 6947 cubic inches. The air guns were shot on distance every $50 \mathrm{~m}$ along each line and on time every $20 \mathrm{~s}$ during turns or air gun-only lines. The air gun array and streamer were towed at 6 and $7 \mathrm{~m}$ depth, respectively.

[9] The instruments used on land were Guralp CMG-6TD, three-component, $30 \mathrm{~s} / 100 \mathrm{~Hz}, 24$ bit digitizer seismometers, with instrument clocks synchronized to GPS. Eighteen of the OBS units were two-component (hydrophone and vertical geophone) El-Cheapo (LC) seismometers supplied by Scripps, and 10 were a version of the LC electronics packaged into large aluminum pressure vessels (DOBS). The latter recorded hydrophone and three-component geophone data.

[10] Processing of the land data consisted of applying a band-pass Ormsby minimum phase filter and a trace dc removal. The passband of the Ormsby filter is defined by corner frequencies: $3-6-30-40 \mathrm{~Hz}$. The sample interval is $10 \mathrm{~ms}$. Processing of the OBS data consisted of applying a band-pass filter with a low pass of $5 \mathrm{~Hz}$ and high pass of $15 \mathrm{~Hz}$, and a $1.0 \mathrm{~s}$ automatic gain control (Figure 2).

[11] From both 1996 and 2005 experiments, a total of 367,790 traveltimes were picked on 56 OBSs and 122 land 
(a)

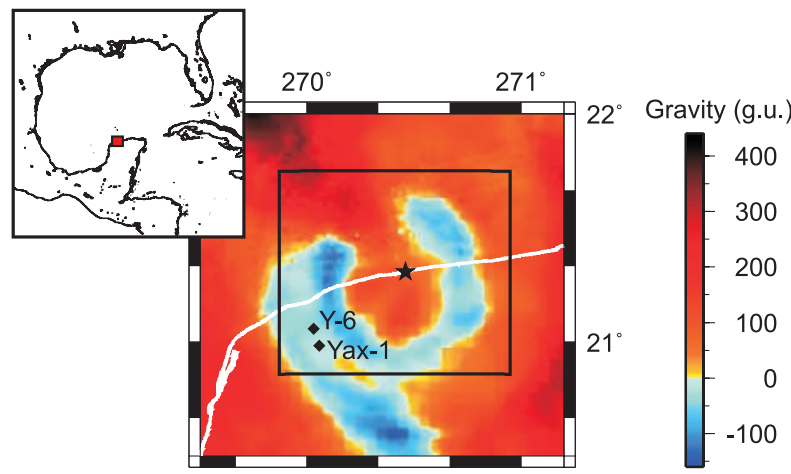

(b)

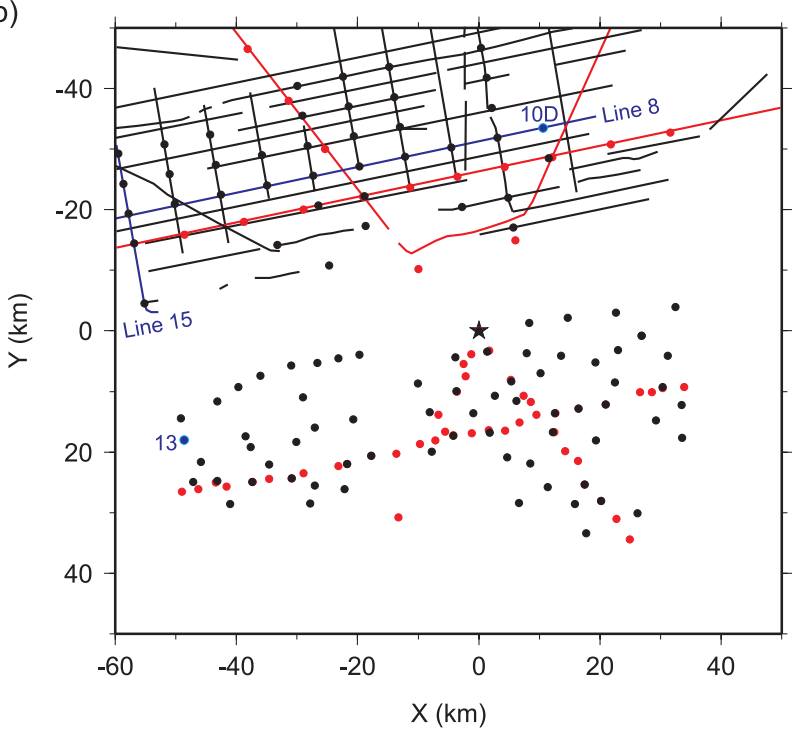

Figure 1. (a) Bouguer gravity anomaly map [Styles, 2006] of the Chicxulub impact structure, with inset map of larger regional location. The extent of the model used throughout this paper is shown as a black rectangle with latitudelongitude (Lat-Lon) corners: $20.86^{\circ} \mathrm{N} / 89.05^{\circ} \mathrm{W}$ and $21.75^{\circ} \mathrm{N} /$ $90.13^{\circ} \mathrm{W}$. The Yucatán coast line is shown in white. Also shown are the ICDP Yaxcopoil-1 (Yax-1) and the Yucatan-6 (Y-6) drill holes and the center of the Chicxulub crater (black star). (b) Refraction data span a model space of $110 \mathrm{~km} \times 100 \mathrm{~km}$, with shot locations (solid lines), OBS locations and land seismometer locations (circles) from the 1996 (red) and 2005 (black) seismic experiments used in our modeling. Blue shots and receivers indicate the 2005 data shown in Figure 2.

seismometers in a $110 \mathrm{~km} \times 100 \mathrm{~km}$ model (Figure 1b). An automated picking program was used for picking the 1996 data and all land data, whereas the 2005 OBS data were picked manually. From the 1996 data we used 65,838 traveltime picks from 61 receivers, whereas from the 2005 data, we used 290,607 traveltime picks from 37 OBSs and 70 land seismometers. The majority of these traveltime picks were assigned a pick uncertainty $\left(\sigma_{i}\right)$ of $50 \mathrm{~ms}$, and the remainder an error of $100 \mathrm{~ms}$. The uncertainty was chosen on the basis of signal-to-noise ratio, which correlated with offset (i.e., signal-to-noise ratio was worst at long offsets). All picked arrivals are crustal phase Pg. There are no obvious first-arrival reflections until the PmP phase, which was not included in the inversion.

[12] The land topography varies from sea level to a maximum of $5 \mathrm{~m}$ above sea level, and the water depth in the region of the velocity model is between 10 and $25 \mathrm{~m}$. Because the traveltime differences due to elevation differences between OBSs and land seismometers is negligible compared to our pick uncertainties, we have assumed that all shots and receivers lie on a flat plane at sea level. The land stations were located with multiple GPS readings and OBSs were located with GPS readings during deployment and recovery. The OBS locations are well constrained in this extremely shallow water, as there is very little drift possible between instrument deployment and seafloor positions.

\subsection{Gravity Data}

[13] The observed gravity is based on a larger Bouguer anomaly map, compiled by Pilkington et al. [1994]. Prior to modeling the gravity data, the latitude (Lat)-longitude (Lon) coordinates were converted to a Cartesian reference system, using the following relationship:

$$
\begin{gathered}
X=101.71 \text { Lon }+9107.56 \\
Y=-112.02 \text { Lat }+2386.67 .
\end{gathered}
$$

[14] The gravity data were smoothed and a 2-D planar regional trend was removed. The 2-D planar trend ranges between -80 in the SE and 97 gravity units (gu, $1 \mathrm{gu}=$ $10^{-6} \mathrm{~m} \mathrm{~s}^{2}=0.1 \mathrm{mGal}$ ) in the NW, corresponding to a trend of $0.17 \mathrm{gu} \mathrm{km}{ }^{-1}$ (increasing eastward) along a profile coinciding with the gravity forward modeling profile of Hildebrand et al. [1998]. This regional trend is half of the 1-D regional trend of $0.35 \mathrm{gu} \mathrm{km}^{-1}$, determined by Hildebrand et al. [1998]. After subtracting the planar grid, the resulting observed gravity ranges between -111 and 221 gu (Figure 3a).

[15] The observed gravity signal has a relative high in the NW corner that extends for over $100 \mathrm{~km}$ and appears to be a regional feature, unrelated to the crater. Previous modeling [Christeson et al., 2001] suggests that this gravity high is associated with regional basement structure which is interpreted to predate the formation of the impact crater. A concentric reflection profile acquired at a constant radial distance of $\sim 85 \mathrm{~km}$ shows that the Tertiary and Cretaceous layers are thinner in the NW direction and thicker in the NE [Collins et al., 2008]. The gravity anomalies in the SE corner are also believed to originate from regional basement structure outside of the model, although this is harder to verify due to the lack of onshore reflection data. In order to exclude gravity signals that may not originate from density differences within the model, the NW and SE parts of the density model have been excluded in the joint inversion (black polygon in Figure 3a).

\section{Method}

\subsection{Slowness-Density Relationship}

[16] To invert traveltime and gravity simultaneously, we need a relationship between slowness (reciprocal of velocity) and density that is representative of the Chicxulub impact 
a)

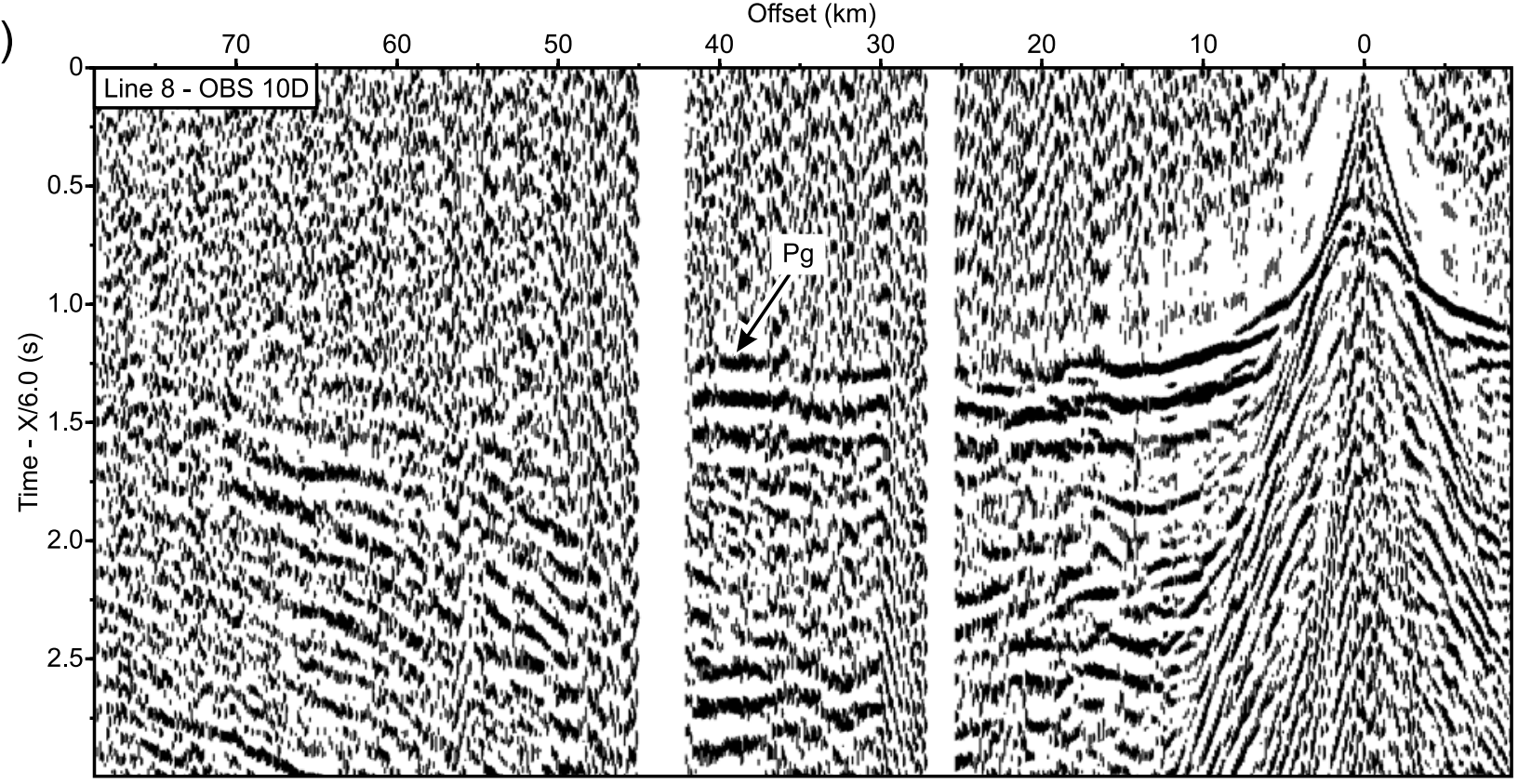

b)

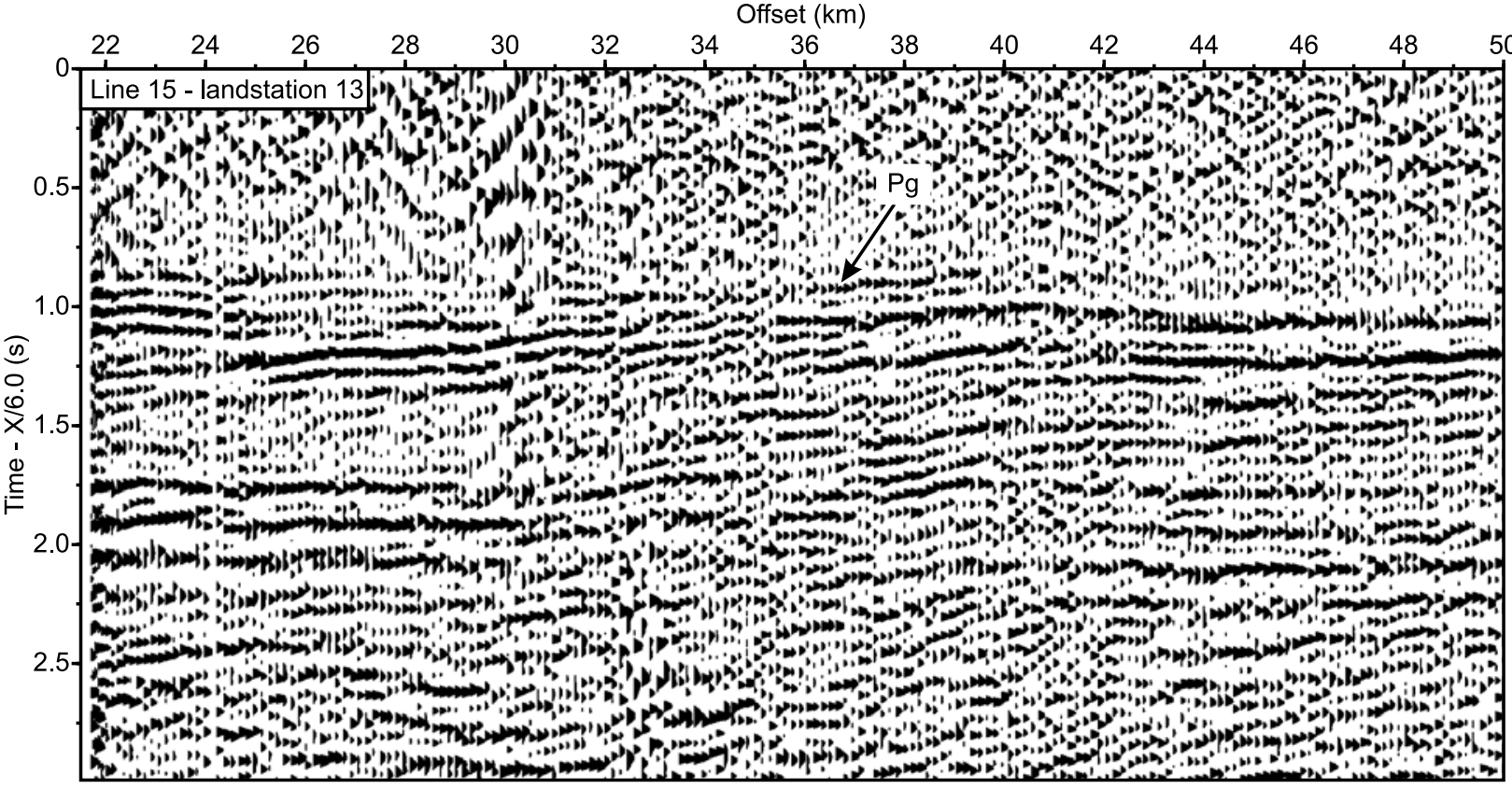

Figure 2. Representative record sections for shots from (a) profile 8, recorded by vertical component of OBS 10D, and (b) profile 15, recorded by vertical component of land station 13. Sections are plotted with a reduction velocity of $6.0 \mathrm{~km} \mathrm{~s}^{-1}$. A band-pass filter was applied, with a low-pass of $5 \mathrm{~Hz}$, high pass of $15 \mathrm{~Hz}$, and a $1.0 \mathrm{~s}$ automatic gain control. Crustal phase Pg is the only phase used in the inversion.

crater lithologies. The velocity and density data used for defining this relationship are from the Yucatan-6 (Y-6) and Yaxcopoil-1 (Yax-1) boreholes (Figure 1a) and their acquisition and analysis are described in detail by P. M. Vermeesch et al. (P-and S-wave velocity measurements of the Chicxulub impact crater lithologies, submitted to Meteoritics and Planetary Science, 2009). Slowness values of the upper basement clasts were used together with slowness values of the Cretaceous sedimentary rocks, impact breccia and Tertiary sedimentary rocks to constrain a linear relationship between slowness and density that is representative for the lithologies encountered at the Chicxulub impact site (Figure 4):

$$
\rho=-3477.8 m+3325.7
$$

with saturated density $(\rho)$ in $\mathrm{kg} \mathrm{m}^{-3}$ and slowness $(m)$ in $\mathrm{s} \mathrm{km}{ }^{-1}$. The maximum deviation of the measured density values from the linear regression curve is 10 and $11 \%$ for the shallow lithologies and the basement clasts, respectively. The densities of melt rock and impact breccia measured by 


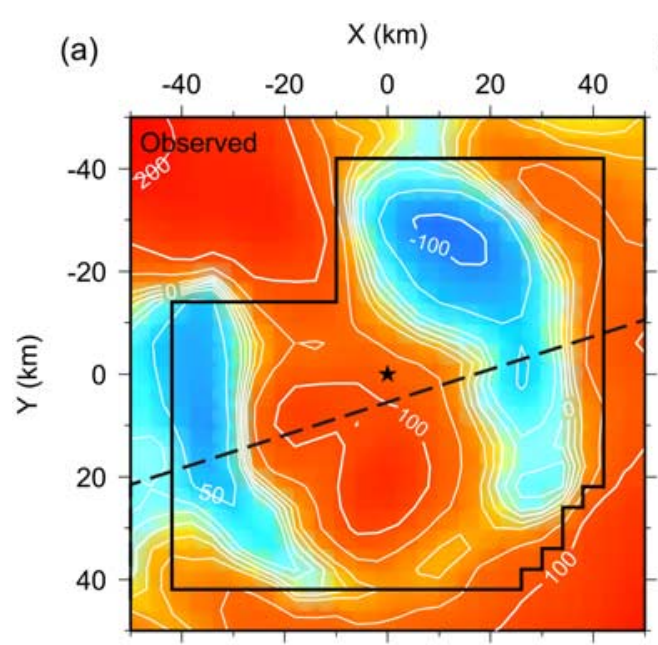

(b)

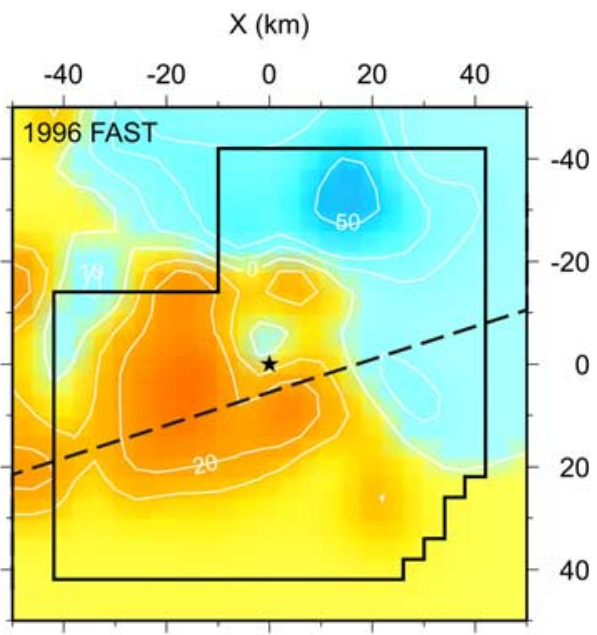

(c)

(d)
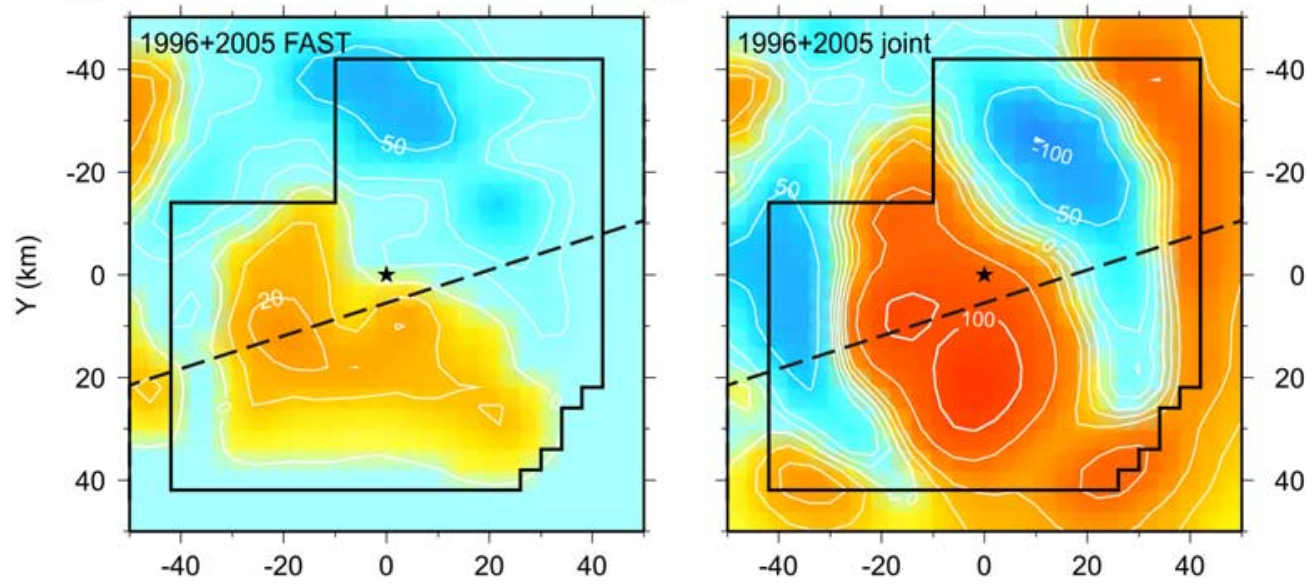

Gravity (g.u.)

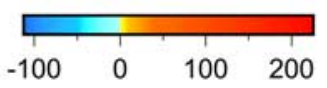

Figure 3. (a) Observed Bouguer gravity anomaly after conversion to a Cartesian reference system, resampling every $4 \mathrm{~km}$, smoothing using a $10 \mathrm{~km}$ wide boxcar filter, and subtraction of a regional trend. Contours are at $-100,50,20,10,0,10,20,50,100$, and $200 \mathrm{gu}$. Also shown is the location of the gravity profile of Hildebrand et al. [1998] (dashed line) and the extent of the gravity data that were used in the inversion (black polygon). (b) The 2-D gravity model calculated from the 1996 FAST traveltime model [Morgan et al., 2000, 2002a]. (c) The 2-D gravity model calculated from the $1996+2005$ FAST traveltime model. (d) The 2-D gravity model calculated from the $1996+2005$ joint model.

V. L. Sharpton (unpublished data, 1995) on samples from the Y-6 core deviate 2 and $13 \%$, respectively.

\subsection{Forward Modeling of Traveltimes}

[17] Forward modeling is defined as the process of predicting $t$ (traveltimes) on the basis of a specific model $m$ (slowness):

$$
F m=t \text {, }
$$

where matrix $F$ contains the lengths of each $i$ th raypath through each cell of the slowness model. The model parameterization for the forward calculation of traveltimes and raypaths is a uniform $0.5 \mathrm{~km}$ cell spacing, resulting in
$221 \times 201 \times 31$ nodes in $X, Y$ and $Z$ directions. We have used the 3-D finite difference eikonal solver of Vidale [1990] with modifications for large velocity gradients by Hole and Zelt [1995], as part of the FAST inversion code developed by Zelt and Barton [1998] and Zelt et al. [2006]. Traveltimes are calculated progressively away from a source on the sides of an expanding cube, one side being completed before the next is considered. The locations of the sources and receivers from the 1996 and 2005 experimental geometry are used (Figure 1b). Raypaths are obtained by following the steepest gradient of the time field from a receiver back to the source [Zelt and Barton, 1998; Vidale, 1988].

[18] To quantify the misfit between observed $\left(t_{i}^{\text {obs }}\right)$ and calculated or predicted $\left(t_{i}^{\text {pre }}\right)$ traveltimes we calculate the 


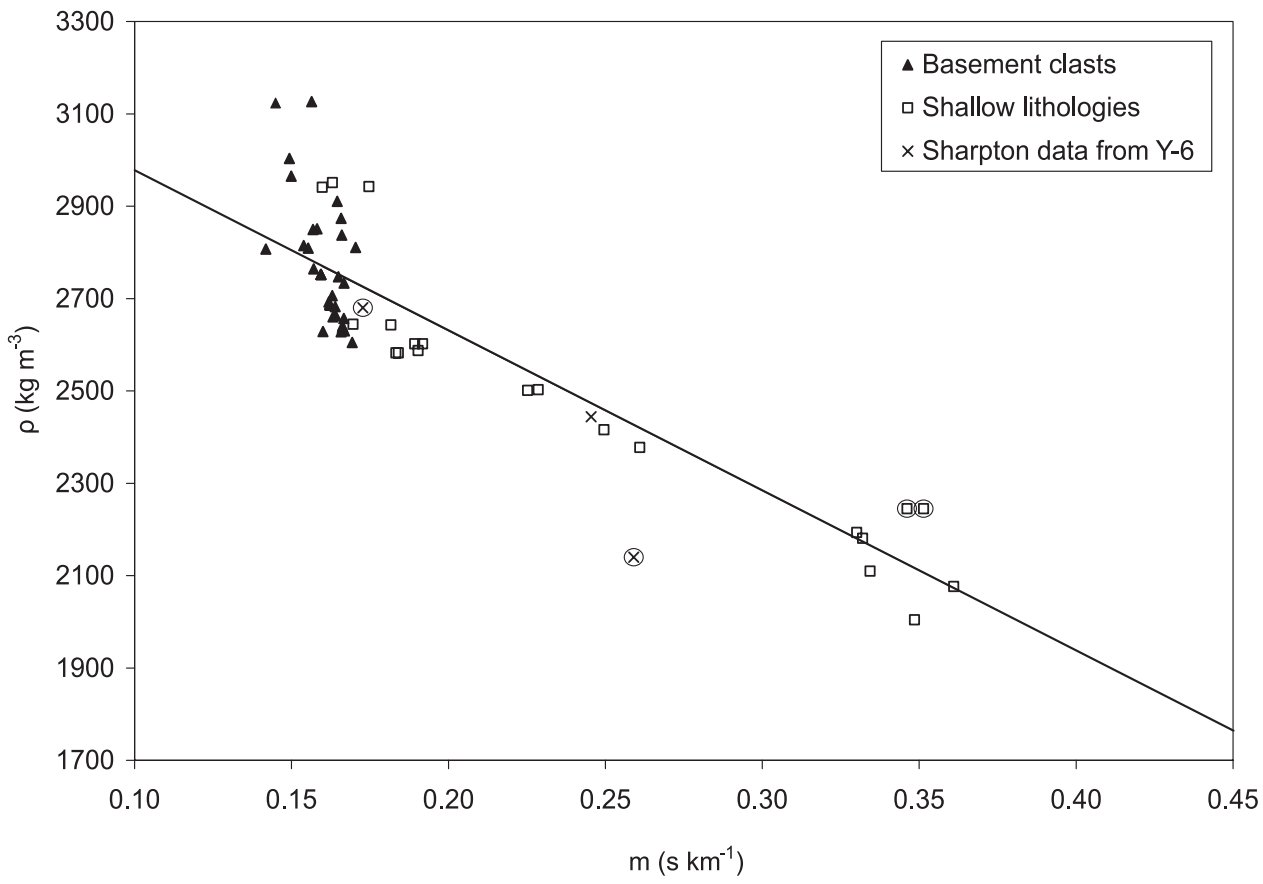

Figure 4. Density $(\rho)$ as a function of slowness $(m)$ for the $\mathrm{P}$ wave velocities from the shallow lithologies of the Yax-1 core (Cretaceous sedimentary rocks, impact breccia, and Tertiary sedimentary rocks) and for the upper basement clasts found in the impact breccia of the Yax-1 and Y-6 cores (for a detailed description of these velocity and density data, see Vermeesch et al. (submitted manuscript, 2009)). Also included are the three measurements on Y-6 samples made by V. L. Sharpton (unpublished data, 1995). Melt rocks and impact breccia data points are circled.

Root Mean Square traveltime misfit $\left(\mathrm{RMS}_{t}\right)$ and normalized traveltime chi-square $\left(\chi_{t}^{2}\right)$ for each $i$ th traveltime pick:

$$
\begin{aligned}
\mathrm{RMS}_{t} & =\sqrt{\frac{1}{N} \sum_{i=1}^{N}\left[t_{i}^{\text {obs }}-t_{i}^{\text {pre }}\right]^{2}} \\
\chi_{t}^{2} & =\frac{1}{N} \sum_{i=1}^{N}\left[\frac{t_{i}^{o b s}-t_{i}^{\text {pre }}}{\sigma_{i}}\right]^{2},
\end{aligned}
$$

where $N$ is 375,787 or the total number of raypaths and $\sigma_{i}$ is the pick uncertainty (either 50 or $100 \mathrm{~ms}$ ). When the traveltime differences of all raypaths approach the pick uncertainty, chi-square will approach a value of 1 . In this case the model fits the traveltime data according to their noise level.

\subsection{Forward Modeling of Gravity}

[19] The vertical component of the gravitational acceleration $\left(g_{i}\right)$ due to a point mass $i$ in a three-dimensional problem is defined as:

$$
g_{i}=\frac{\rho_{i} V G z}{\sqrt[3]{x^{2}+y^{2}+z^{2}}},
$$

where $G$ is the gravitational constant, $\rho_{i} V$ is density $\times$ volume (= mass), and $x, y, z$ are the distances between the point mass $i$ and our observation point $k$ in a Cartesian coordinate system.
To calculate the gravity of a 3-D density model $i$ at any point at the surface $k$, we need to sum the vertical component due to all cells (assumed point masses) at that particular point at the surface.

[20] The gravity anomaly at any point at the surface is derived from lateral density differences in the subsurface. The density difference is calculated with regard to a background or reference density model, which can be derived from a reference slowness model using equation (2). Hence, we obtain

$$
\delta \rho_{i}=-3477.8 \times \delta m_{i}
$$

with $\delta \rho$ the lateral density difference model and $\delta m$ the difference between the slowness model $m$ and the reference slowness model $m_{0}$ (Figure 5). The reference slowness model is calculated by taking the reciprocal of the 1-D starting velocity model used in the inversions in this paper and by Morgan et al. [2000, 2002a], and Vermeesch and Morgan [2008]. Equation (6) now becomes

$$
\delta g_{i}=\frac{-3477.8 \delta m_{i} V G z}{\sqrt[3]{x^{2}+y^{2}+z^{2}}}
$$

[21] The forward problem can be expressed in matrix form as

$$
E \delta m=\delta g,
$$




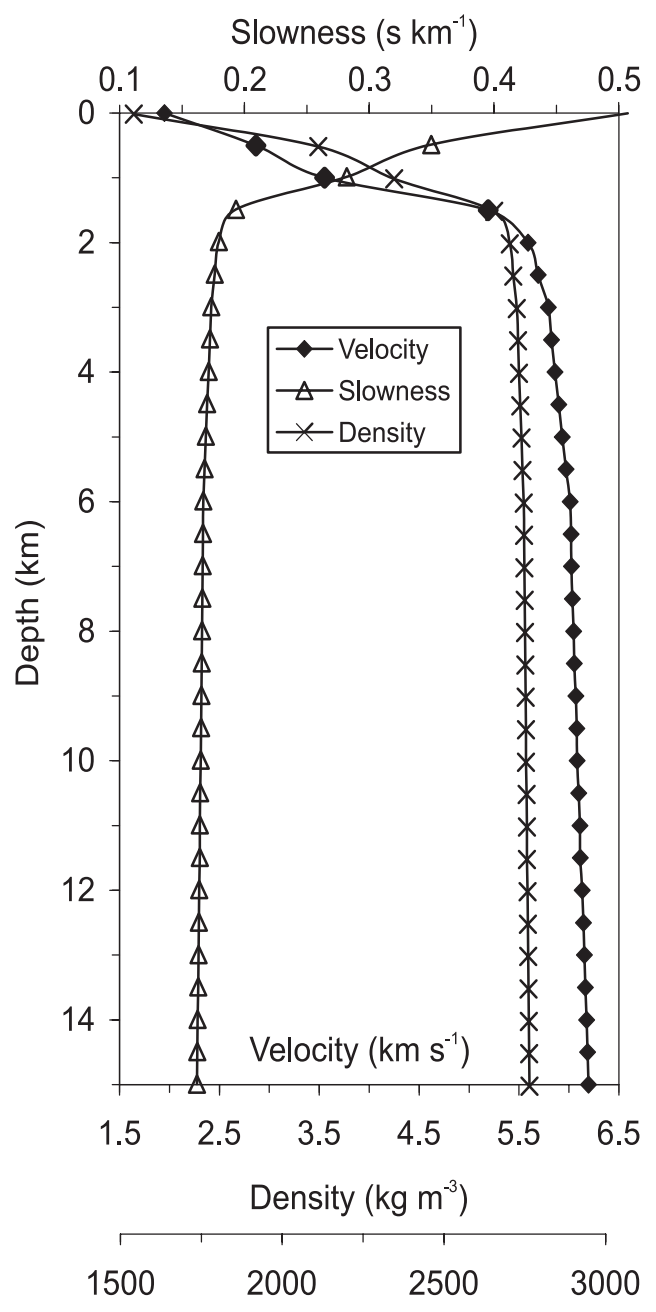

Figure 5. The 1-D starting model. This velocity model is an average of the 3-D model obtained from the 1996 refraction data by Morgan et al. [2000]. From this, slowness $\left(\mathrm{s} \mathrm{km}{ }^{-1}\right)$ is calculated as the reciprocal of velocity, and density $\left(\mathrm{kg} \mathrm{m}^{-3}\right)$ is calculated using equation (2).

where $E$ is the matrix relating slowness to gravity for every gravity anomaly $k$ and every model parameter $i$ :

$$
E_{k, i}=\frac{-3477.8 V G z}{\sqrt[3]{x^{2}+y^{2}+z^{2}}}
$$

[22] In analogy to equations (4) and (5), we define the RMS misfit between observed $\left(g_{k}^{o b s}\right)$ and predicted $\left(g_{k}^{\text {pre }}\right)$ gravity, and the normalized gravity chi-square:

$$
\begin{aligned}
\mathrm{RMS}_{g} & =\sqrt{\frac{1}{M} \sum_{k=1}^{M}\left[g_{k}^{o b s}-g_{k}^{p r e}\right]^{2}}, \\
\chi_{g}^{2} & =\frac{1}{M} \sum_{k=1}^{M}\left[\frac{g_{k}^{o b s}-g_{k}^{p r e}}{\sigma_{k}}\right]^{2},
\end{aligned}
$$

where $M$ is 327 or the total number of gravity values at surface, and $\sigma_{k}$ is the gravity data uncertainty, here set to
$10 \mathrm{gu}$. The model parameterization for the forward calculation of gravity is a uniform $4 \mathrm{~km}$ cell spacing. The reason for a larger cell size is due to computing restraints, but since we are interested in the large-scale anomalies from the deeper structure of the central Chicxulub crater, we believe that this does not present a major problem. To avoid edge effects, it was decided not to use the outer 2 cells or $8 \mathrm{~km}$ of the calculated surface gravity anomaly (see black polygon in Figure 3). A comparison between the gravity anomalies calculated from the velocity model published by Morgan et al. [2000] (Figure 3b) and the observed anomalies (Figure 3a) shows that both have a pronounced gravity low in the NE corner of the model and a pronounced gravity high in the SW corner, and that the low is $\sim 50$ gu higher and the high is $\sim 80 \mathrm{gu}$ lower than observed. $\mathrm{RMS}_{g}$ and $\chi_{\mathrm{g}}^{2}$ are $52 \mathrm{gu}$ and 27 , respectively. When we compare the difference between maximum and minimum values of the observed model with that of the calculated model, we see that only $30 \%$ of maximum gravity difference is recovered and $70 \%$ is lost.

[23] To investigate which parts of the density model are responsible for the observed gravity anomalies, the gravity anomaly was calculated from different depth slices of $1 \mathrm{~km}$ thickness of the velocity model published by Morgan et al. [2000]. These calculations showed that the low gravity signature in the NE originates predominantly from shallow depths between 0 and $2 \mathrm{~km}$ depth and to a lesser extent between 2 and $4 \mathrm{~km}$. The high gravity zone in the SW originates from all depths between 0 and $8 \mathrm{~km}$, but its highest contribution comes from depths between 3 and $7 \mathrm{~km}$. There is no gravity signature from deeper slices because the velocity model is not resolved at depths $>7 \mathrm{~km}$. Since the calculated gravity high is underestimated, we expect that the highvelocity zone (HVZ) in the velocity model must extend deeper than imaged by traveltime tomography.

\subsection{Regularized Inversion}

[24] The term inversion is used in contrast to forward modeling, where the model parameters $(m)$ are known and the data $(t)$ can be predicted using the operator or function $F$ (equation (3)). Inverse theory addresses the reverse problem: starting with data $(t)$, it determines estimates of the model parameters $(m)$.

[25] Traveltime inversion is a nonlinear problem because the raypaths are dependent on the slowness model. Therefore, a linearized iterative approach is applied, using a Taylor's series expansion in which a starting model is required. Expanding the nonlinear equation $F m=t$ about some point in model space $\left(m_{0}\right)$ using Taylor's theorem, we obtain

$$
F m \approx F m_{0}+\nabla F\left[m-m_{0}\right]
$$

with $m_{0}$ an initial guess of the model parameters, i.e., the starting model. Note that $F m=t^{o b s}$ are the observed data, and $F m_{0}=t^{\text {pre }}$ are the predicted or calculated data. $\nabla F=F_{0}$ is the partial derivative matrix of the data with respect to the model parameters:

$$
\left[F_{0}\right]_{i j}=\frac{\delta t_{i}}{\delta m_{j}}
$$


The nonlinear problem $\mathrm{Fm}=t$ can thus be rewritten as

$$
\begin{gathered}
t^{o b s}=t^{p r e}+F_{0} \delta m \\
\delta t=F_{0} \delta m,
\end{gathered}
$$

with $\delta t$ the vector of traveltime residuals (i.e., the difference between observed and predicted traveltime for each sourcereceiver pair), and $\delta m$ the vector of slowness perturbation values: $m-m_{0}$. This linear inversion problem is then solved for the slowness perturbation or model update $(\delta m)$, and the model update is added to the starting model to obtain a new model of slowness. This method is called an iterative linearized inversion. The model and raypaths are updated over a series of iterations until the normalized misfit $\left(\chi_{t}^{2}\right)$ between the observed and calculated data ideally reaches 1 .

[26] The method used in the FAST inversion of Zelt and Barton [1998] is a regularized iterative linearized inversion. Regularization is an approach by which constraints, in addition to the data, are applied to an inverse problem to treat the underdetermined part of the solution [Zelt and Barton, 1998; Scales et al., 1990]. At each iteration, an objective function $\phi(m)$, which measures a combination of the data misfit and the structure of the model, is minimized in the least squares sense. The FAST inversion used as a starting point for this joint inversion method is the slightly modified version described by Zelt et al. [2006], which includes a norm for model perturbation as well as norms for the horizontal and vertical smoothness of the slowness model. In the joint inversion adapted from FAST, we minimize an objective function $\phi(\delta m)$ that includes the data misfit (equations (16) and (9)) in conjunction with norms for $\delta m$ that limit the model smoothness and perturbation:

$$
\phi(\delta m)=\left\|\begin{array}{c}
C_{t}^{-\frac{1}{2}}\left(F_{0} \delta m-\delta t\right) \\
\beta C_{g}^{-\frac{1}{2}}(E \delta m-\delta g) \\
\lambda \alpha C_{h}\left(m_{0}+\delta m\right) \\
\lambda \alpha s_{z} C_{v}\left(m_{0}+\delta m\right) \\
\lambda(1-\alpha) I \delta m
\end{array}\right\|^{2}
$$

with $C_{t}$ and $C_{g}$ the traveltime and gravity data covariance matrices containing data variances $\sigma_{i}^{2}$ and $\sigma_{k}^{2}$. To find the simplest model, i.e., the model closest to the starting or current model $m_{0}$, and to avoid modeling artifacts, a damping parameter is included that contains the identity matrix $I$. By letting the horizontal and vertical smoothness matrices $C_{h}$ and $C_{v}$ operate on $m_{0}+\delta m$ we impose constraints on the smoothness of the future model $m$ instead of on $m_{0}$. The smoothness matrices $C_{h}$ and $C_{v}$ are second-order spatial finite difference operators [Zelt et al., 2006].

[27] The parameters $\lambda, s_{z}, \alpha$ [Zelt et al., 2006] and $\beta$ control the weight of the terms in the objective function. The Tikhonov trade-off parameter $\lambda$ defines the relative weighting between data misfit and overall amount of regularization and is reduced systematically at every iteration throughout the inversion. In the final iteration $\lambda$ is chosen such that we obtain the minimum structure model from all models that adequately fit the data according to their noise level. $s_{z}, \alpha$ and $\beta$ are held fixed for all iterations leading to a final model. $s_{z}$ determines the relative weighting between horizontal and vertical smoothing constraints [Zelt et al., 2006]. A value of 0 eliminates any constraint on vertical smoothness and a value of 1 gives equal constraints in both the vertical and horizontal directions. A value between 0 and 1 allows vertical velocity changes more easily than horizontal ones, whereas a value greater than 1 allows horizontal velocity changes more easily than vertical ones. The parameter $\alpha$ determines the relative weighting between damping and smoothness constraints [Zelt et al., 2006]. $\alpha$ can have any value between 0 and 1 , with 1 for an inversion without perturbation constraints [Zelt and Barton, 1998] and 0 for an inversion without smoothing constraints. The parameter $\beta$ does not exist in the original FAST inversion, but is introduced in the joint inversion to define the relative weighting between gravity and traveltime misfit. To establish the best value for this new weighting parameter, different values of $\beta$ are explored using synthetic tests.

[28] The following system of equations is derived by minimizing equation (17) with respect to the model parameters:

$$
\left[\begin{array}{c}
C_{t}^{-\frac{1}{2}} F_{0} \\
\beta C_{g}^{-\frac{1}{2}} E \\
\lambda \alpha C_{h} \\
\lambda \alpha s_{z} C_{v} \\
\lambda(1-\alpha) D
\end{array}\right] \delta m=\left[\begin{array}{c}
C_{t}^{-\frac{1}{2}} \delta t \\
\beta C_{g}^{-\frac{1}{2}} \delta g \\
-\lambda \alpha C_{h} m_{0} \\
-\lambda \alpha s_{z} C_{v} m_{0} \\
0
\end{array}\right] .
$$

At every iteration $\delta m$ is calculated using the LSQR algorithm for sparse linear equations and sparse least squares [Paige and Saunders, 1982]. For the inverse step, the model is divided into cells of constant slowness, with cell size of $1 \mathrm{~km} \times 1 \mathrm{~km} \times 0.5 \mathrm{~km}$ in the $X, Y$, and $Z$ directions, resulting in 330,000 model parameters in a 3-D model that spans $110 \mathrm{~km} \times 100 \mathrm{~km} \times 15 \mathrm{~km}$.

\section{Results From Synthetic Tests}

[29] Synthetic traveltime data were calculated from a test model, comprising a HVZ with a flat top and equal width at all depths (Figures 6a and 6b). The synthetic model was constructed so that it had a comparable velocity contrast to the observed results from previous inversions, and was located in the same place relative to the experimental geometry as the HVZ in the model derived from the observed data. Normally distributed, random noise was added, and the synthetic traveltime data were then inverted using the FAST inversion code of Zelt et al. [2006] and the joint inversion described in this paper. The purpose of these tests is to provide an indication of what features can and cannot be recovered using both methods, and determine which values of the weighting parameters result in the best recovery of central crater structure. To examine the effect of experimental geometry on resolution, these tests were carried out using the 1996 experimental geometry only and the combined geometry for both 1996 and 2005 experiments.

\subsection{Synthetic Tests: Traveltime Inversion}

[30] Synthetic tests showed that the FAST traveltime inversion cannot resolve a HVZ with a flat top at $3.5 \mathrm{~km}$ 

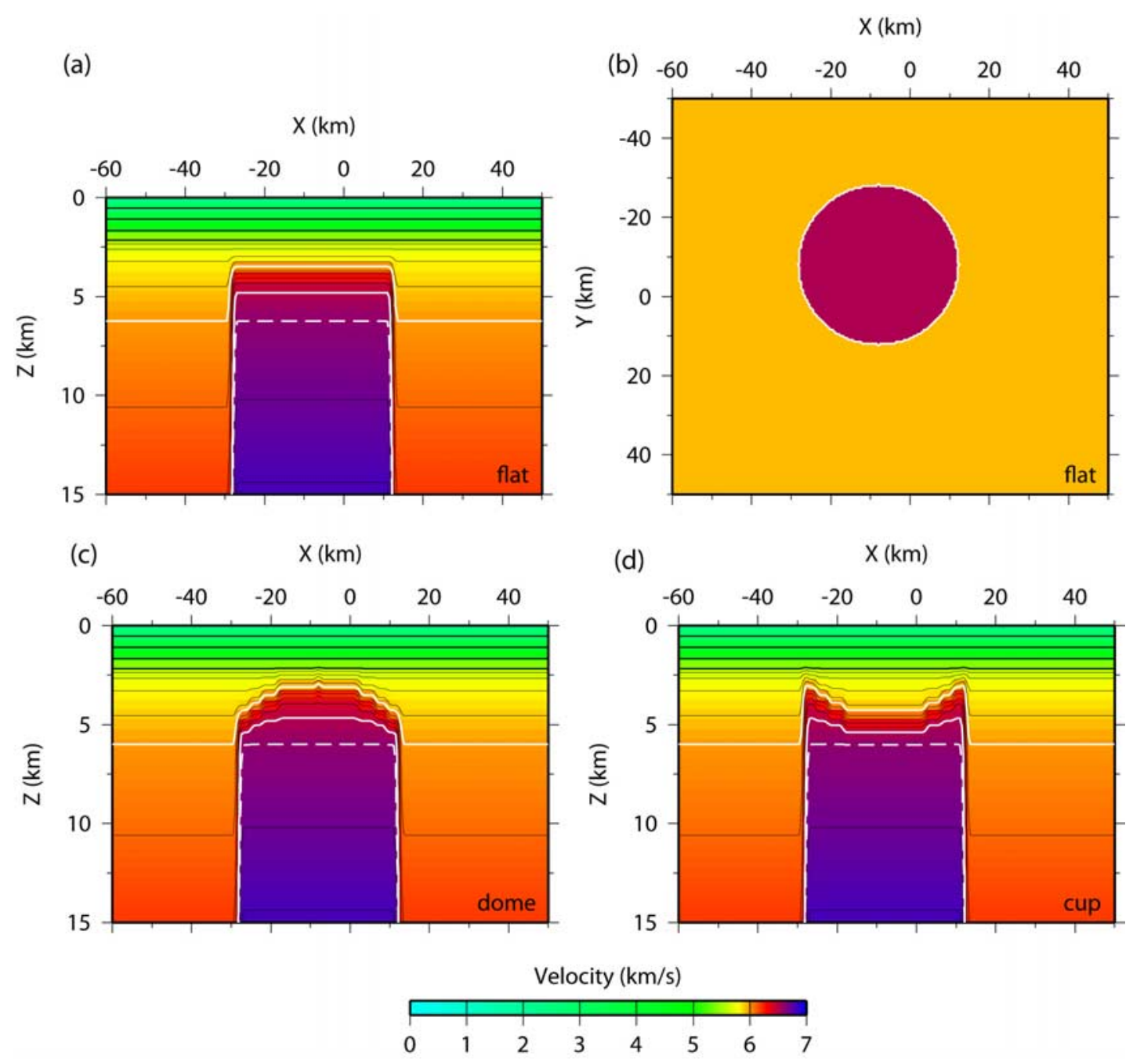

Figure 6. Test models comprising a central uplift with (a, b) a flat top at $3.5 \mathrm{~km}$ depth; (c) a dome-shaped or concave downward top between 3 and $5 \mathrm{~km}$ depth; and (d) a cup-shaped or concave upward top between 3 and $5 \mathrm{~km}$ depth. The test models have equal width of $40 \mathrm{~km}$ at depths greater than $5 \mathrm{~km}$, created by adding a disk-shaped velocity anomaly to the starting velocity model in Figure 5 . The disk is centered around $X=$ $-8 \mathrm{~km}=Y$ to imitate the location of the central uplift observed in the final velocity model from Morgan et al. [2000]. A $10 \%$ increase in velocity is added for all cells within the disk. Thick black contours are shown every $1 \mathrm{~km} \mathrm{~s}^{-1}$, and thin black contours are shown every $0.1 \mathrm{~km} \mathrm{~s}^{-1}$. Solid white contours are 6.0 and $6.5 \mathrm{~km} \mathrm{~s}^{-1}$, and the dashed white contour is $6.6 \mathrm{~km} \mathrm{~s}^{-1}$.

depth using the 1996 seismic experimental geometry (Figures $7 \mathrm{a}$ and $7 \mathrm{~b}$ ). Instead, a concave-upward or cupshaped top is recovered in the N-S profile, with a relief of up to $1.5 \mathrm{~km}$ of the $6.0 \mathrm{~km} \mathrm{~s}^{-1}$ contour (Figure $7 \mathrm{~b}$ ). The $6.5 \mathrm{~km} \mathrm{~s}^{-1}$ contour is poorly resolved in all parts of the model. When the synthetic tests are carried out using the more regular 2005 experimental geometry (Figures $7 \mathrm{c}$ and $7 \mathrm{~d}$ ), the artifact is reduced to a relief of up to $0.7 \mathrm{~km}$ of the $6.0 \mathrm{~km} \mathrm{~s}^{-1}$ contour in the S part only of the N-S profile (Figure 7d). For this reason the artifact is believed to be caused mostly by the irregular geometry of the 1996 experiment (Figure 1b). We conclude that the shape of the top of the central uplift cannot be accurately recovered in the S part of the model using the 1996 and 2005 refraction data. This is mainly due to the fact that we have no shots on land, resulting in a lack of raypaths with different azimuths, and thus poor resolution [Morgan et al., 2002a]. We are, however, better able to image the true shape of the central uplift using the new data acquired in 2005 in the north, west, and east parts of the model, and the $6.5 \mathrm{~km} \mathrm{~s}^{-1}$ contour is also better resolved in all parts of the model, compared to the 1996 data. The synthetic tests clearly indicate that the correct depth to the top of the 6.0 and $6.5 \mathrm{~km} \mathrm{~s}^{-1}$ contours is recovered within $0.5 \mathrm{~km}$. Because of inherent smoothing of the traveltime inversion, the $6.0 \mathrm{~km} \mathrm{~s}^{-1}$ contour is up to $0.5 \mathrm{~km}$ too shallow whereas the $6.5 \mathrm{~km} \mathrm{~s}^{-1}$ contour is up to $0.5 \mathrm{~km}$ too deep. The recovery of the HVZ in the 3-D synthetic tests presented here is much better than that observed in similar 2-D synthetic tests, in which the top of the recovered central uplift was up to $1.5 \mathrm{~km}$ too deep [Christeson et al., 2001].

[31] The maximum velocity value in the upper part of the HVZ in the test model $\left(>6.6 \mathrm{~km} \mathrm{~s}^{-1}\right)$ is not recovered, but instead a zone of velocities $>6.5 \mathrm{~km} \mathrm{~s}^{-1}$ is imaged at the 

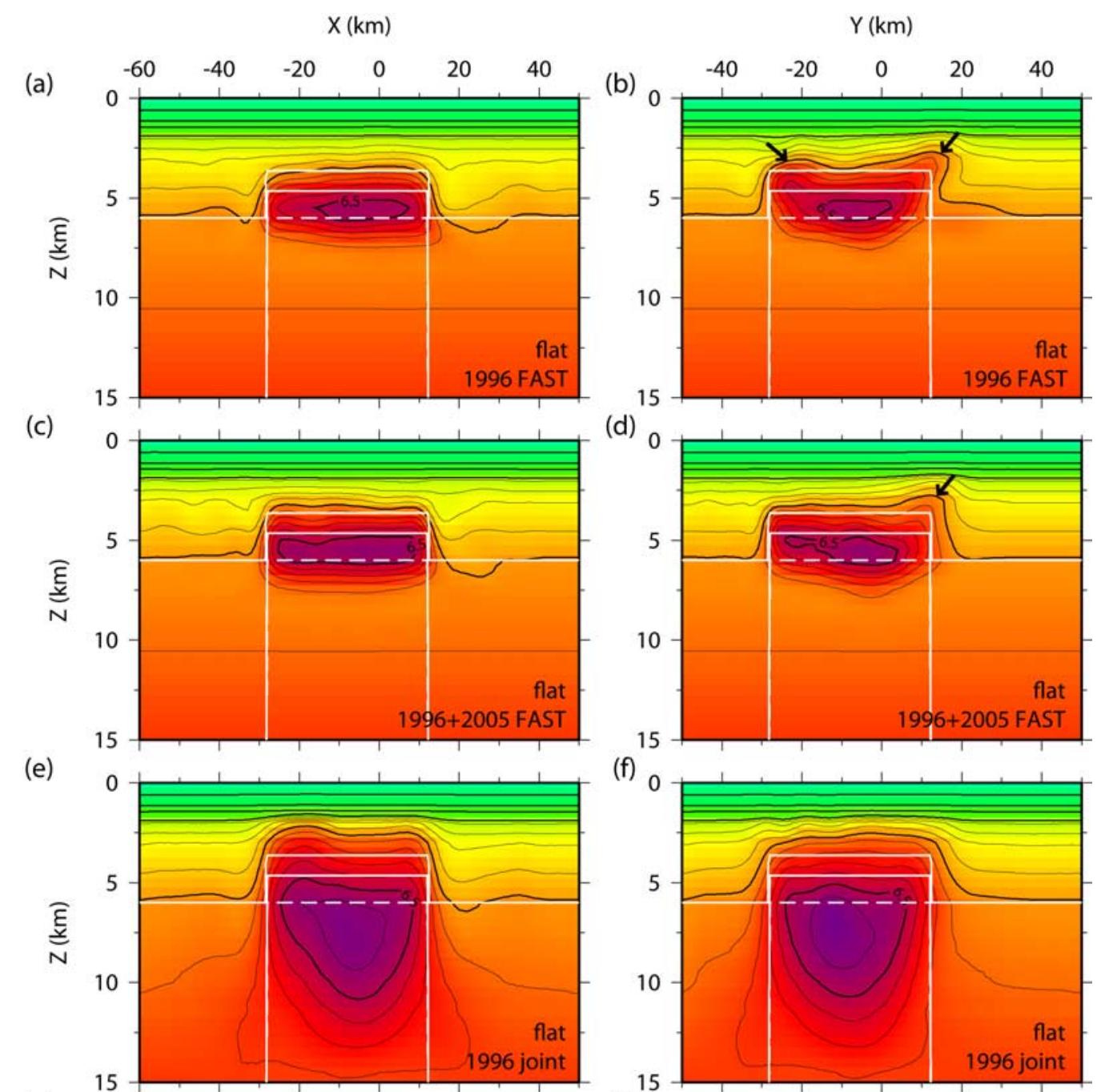

(d)
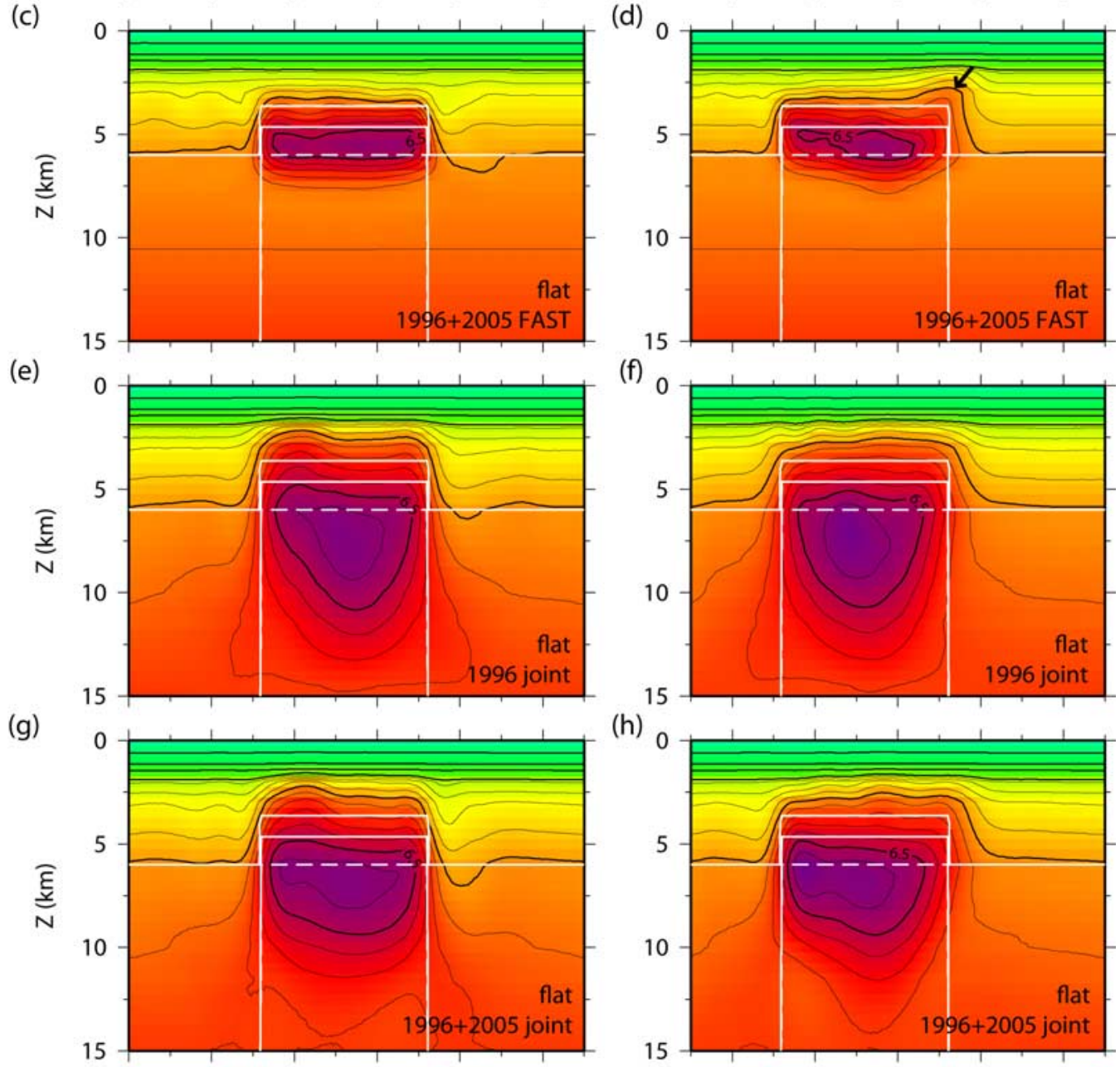

(h)
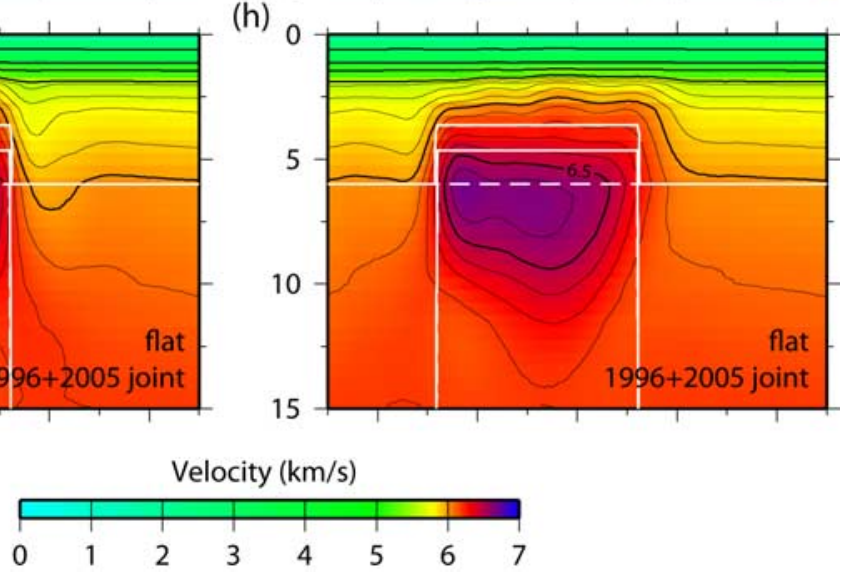

Figure 7. Inversion results of the synthetic traveltime data from the flat-topped test model in Figures 6a and $6 \mathrm{~b}$ for $(\mathrm{a}, \mathrm{b})$ the 1996 experimental geometry and the FAST traveltime inversion, (c, d) the 1996 and 2005 experimental geometries and the FAST traveltime inversion, (e, f) the 1996 experimental geometry and the joint inversion, and (g, h) the 1996 and 2005 experimental geometries and the joint inversion. Slices are at $Y=-8 \mathrm{~km}$ and $X=-8 \mathrm{~km}$. Thick black contours are shown every $1 \mathrm{~km} \mathrm{~s}^{-1}$, and thin black contours are shown every $0.1 \mathrm{~km} \mathrm{~s}^{-1}$. For comparison, the flat test model is indicated by solid $(6.0$ and $\left.6.5 \mathrm{~km} \mathrm{~s}^{-1}\right)$ and dashed $\left(6.6 \mathrm{~km} \mathrm{~s}^{-1}\right)$ white contours. Black arrows indicate the artifact resulting from the 1996 experimental geometry when using the FAST traveltime inversion. 


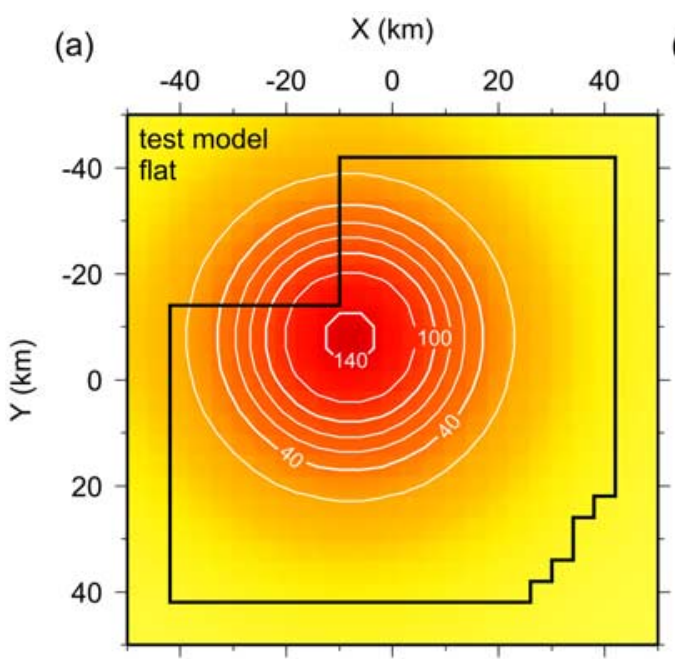

(b)

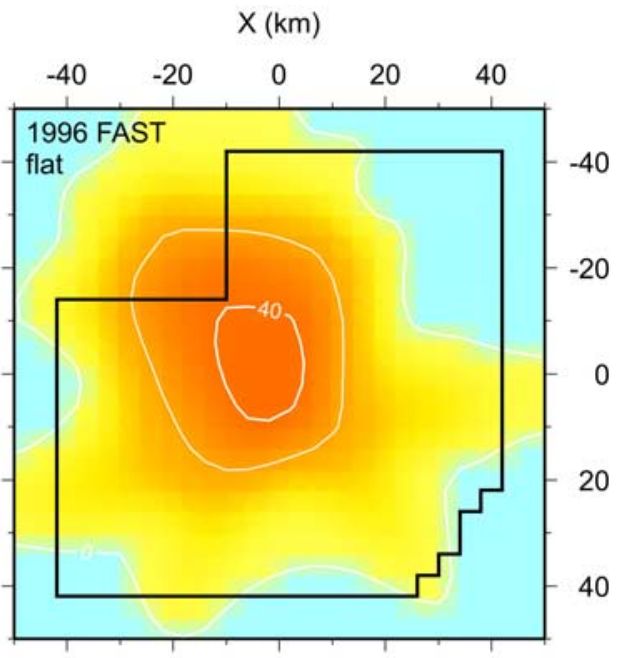

(c)

(d)
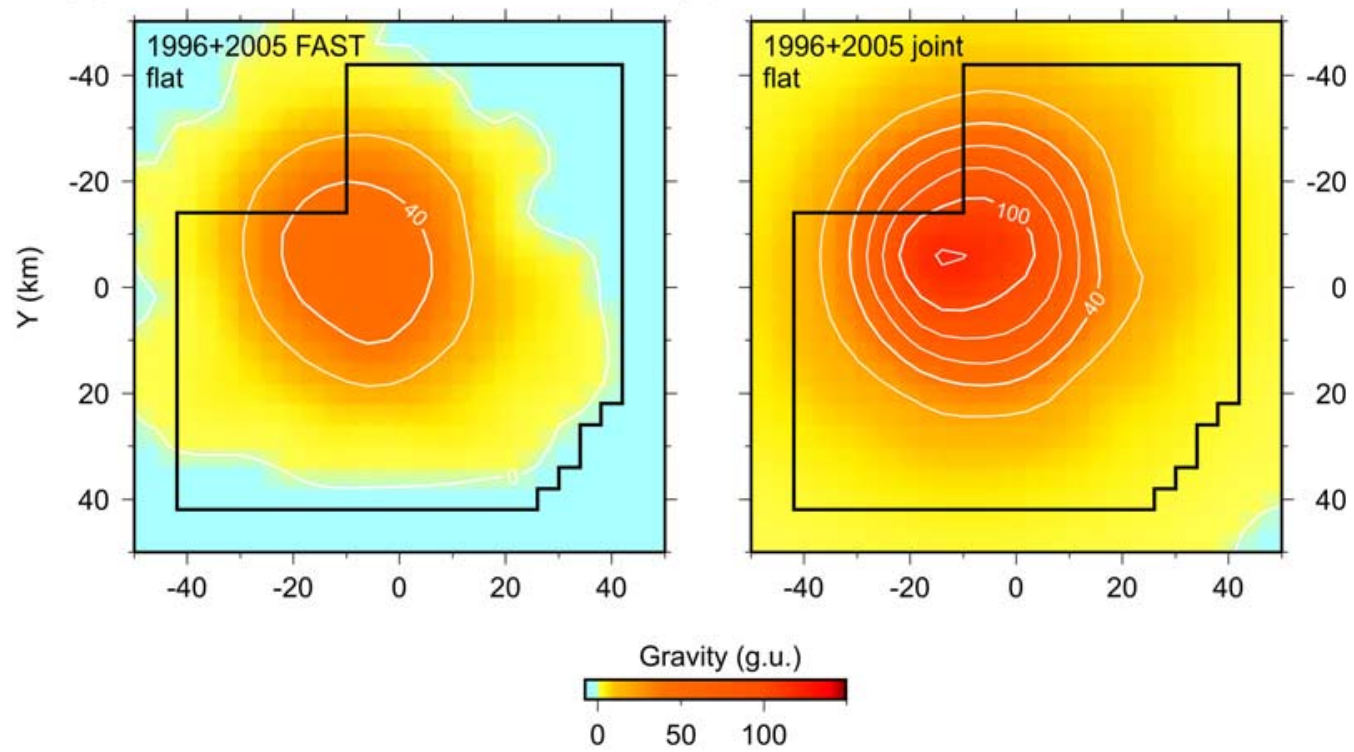

Figure 8. (a) The 2-D gravity model calculated at the surface from the 3-D synthetic flat-topped test model in Figures $6 \mathrm{a}$ and $6 \mathrm{~b}$. The extent of the gravity data that were used in the inversion is indicated by the black polygon. (b) The 2-D gravity model calculated from the synthetic test results using the FAST traveltime inversion and the 1996 experimental geometry only. (c) The 2-D gravity model calculated from the synthetic test results using the FAST traveltime inversion and the combined geometry of the 1996 and 2005 experiments. (d) The 2-D gravity model calculated from the synthetic test results using the joint inversion and the combined geometry of the 1996 and 2005 experiments. Contours are every 20 gu.

correct depth within $0.5 \mathrm{~km}$. From this, it is concluded that the upper part of the HVZ in the inversion of the observed data is likely to be formed from material with a velocity slightly higher $\left(\sim 0.1 \mathrm{~km} \mathrm{~s}^{-1}\right)$ than the maximum velocity recovered and that these velocities extend across the entire width.

[32] When comparing the gravity anomalies calculated from the resolved velocity models with the gravity anomalies calculated from the test model, we see that only $36 \%$ of the gravity anomaly is recovered (Figures $8 \mathrm{~b}$ and $8 \mathrm{c}$ ). This is expected for two reasons: (1) the inverted velocity model is smoothed, i.e., synthetic tests show that the maximum or minimum velocities are not recovered and this leads to a reduction in the magnitude of the gravity anomalies; and
(2) we cannot resolve any structure deeper than $7 \mathrm{~km}$ due to the lack of raypaths at these depths. There is no easy way to distinguish the relative contribution of these two issues in observed gravity data, but we can make estimates of what it might be from synthetic tests. In our synthetic test model (Figure 8 a) $37 \%$ of the gravity signal is generated from density differences above $7 \mathrm{~km}$ depth and $63 \%$ is generated from density differences below $7 \mathrm{~km}$ depth. This indicates that nearly all of the loss of the magnitude of gravity anomaly (63 out of $70 \%$ ) in the traveltime models from observed data is due to the lack of structure and thus the lack of ray coverage below $7 \mathrm{~km}$ depth.

[33] Using the irregular 1996 experimental geometry results in an asymmetric noncircular gravity anomaly 


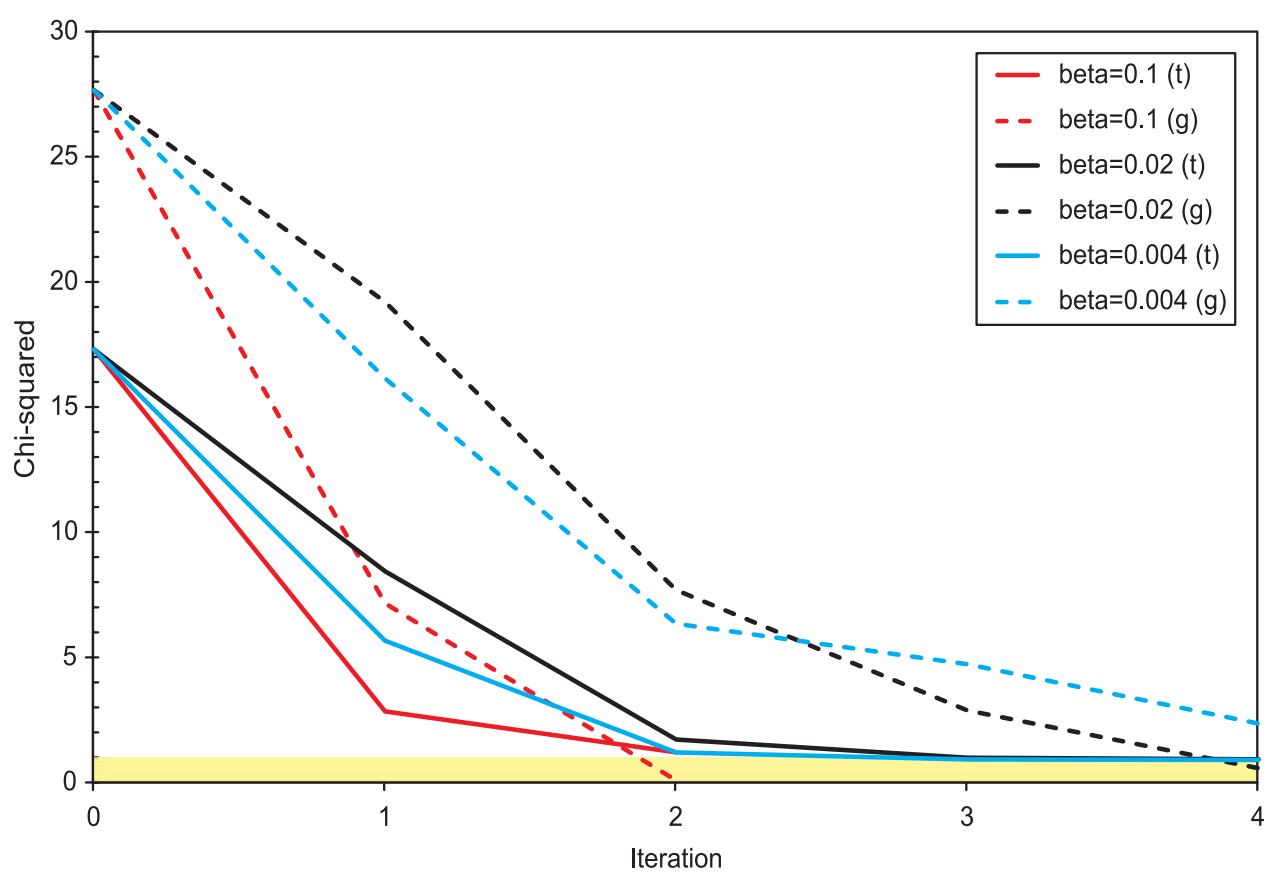

Figure 9. Inversion results of the synthetic traveltime data from the flat-topped test model in Figures 6a and $6 \mathrm{~b}$ for the 1996 and 2005 experimental geometries and the joint inversion. Chi-square values for traveltimes $\left(\chi_{t}^{2}\right)$ and gravity $\left(\chi_{g}^{2}\right)$ versus iteration number for different values of the weighting parameter $\beta$ : $0.004,0.02$, and 0.1 . The yellow rectangle indicates the range of models that are fitted according to their noise ratio $\left(\chi^{2}=1\right)$ and that are over fitted $\left(\chi^{2}<1\right)$.

(Figure 8b). Including the more regular 2005 experimental geometry in our inversion allows us to resolve the circular gravity anomaly from the test model slightly better (Figure 8c).

\subsection{Synthetic Tests: Joint Inversion}

[34] To determine the optimum weighting between gravity and traveltime constraints (new parameter $\beta$ ), synthetic traveltime and synthetic gravity data were calculated from the test model in Figures $6 \mathrm{a}$ and $6 \mathrm{~b}$ and then inverted using the joint inversion and the combined geometries of the 1996 and 2005 experiments for different values of $\beta$. Higher values of $\beta$ result in an increased weighting of the gravity misfit, whereas lower values of $\beta$ result in an increased weighting of the traveltime misfit. To obtain a similar order of magnitude for both gravity and traveltime misfits normalized by their respective data uncertainties, $\beta$ would need to have a value of 0.006 . This, however, does not mean that gravity and traveltime misfit have equal weighting in the inversion because the number of traveltime measurements $(N=375,787)$ is several orders of magnitude larger than the number of gravity measurements $(\mathrm{M}=327)$. To find the optimal value of $\beta$, several synthetic tests were carried out in which $\beta$ was set to values between 0.004 and 0.1 . As expected, the largest influence of $\beta$ is on which data set is fitted best. When we use a low value of 0.004 , the traveltime data are fitted after 4 iterations $\left(\chi_{t}^{2}=1.0\right)$, while the gravity misfit $\left(\chi_{g}^{2}\right)$ is 2.5 (Figures $9,10 \mathrm{a}$, and $10 \mathrm{~b}$ ). A higher $\beta$ of 0.1 results in the gravity data being over-fitted after 2 iterations $\left(\chi_{g}^{2}=0.2\right.$ ), while $\chi_{t}^{2}$ is 1.3 (Figures $9,10 \mathrm{c}$, and 10d). Ideally, we want to use a value of $\beta$ for which the gravity and traveltime misfits both improve gradually and reach a chi-square of 1 simultaneously. In this case, the resulting velocity/density model would fit both data sets according to their respective noise ratio. Using a value of 0.02 achieves this best: after 4 iterations $\chi_{t}^{2}$ is 1.0 and $\chi_{g}^{2}$ is 0.7 (Figures $7 \mathrm{~g}, 7 \mathrm{~h}$, and 9). The synthetic tests show that the true location of the 6.5 and $6.6 \mathrm{~km} \mathrm{~s}^{-1}$ contours and thus the shape and extent of the top of the HVZ are recovered best when more weighting is given to the traveltime misfit (Figures 10a and 10b), whereas contours extend deeper and are more smoothed when more weighting is given to the gravity misfit (Figures 10c and 10d).

[35] For comparison, synthetic traveltime and synthetic gravity data were also inverted using the joint inversion and the 1996 experimental geometry only (Figures 7e and 7f). The parameters that resulted in the best overall fit of traveltime and gravity data are: $\beta=0.02, s_{z}=2$ and $\alpha=1.0$. The 1-D starting model is an average of the $3-\mathrm{D}$ velocity model obtained from the 1996 refraction data. It is the same starting model as used by Morgan et al. [2000] (Figure 5).

[36] In contrast to the FAST traveltime inversion, the joint inversion is not successful in recovering the correct depth to the top of the HVZ 6.0 and $6.5 \mathrm{~km} \mathrm{~s}^{-1}$ contours. It does, however, recover the correct maximum velocity in the top of the HVZ $\left(>6.6 \mathrm{~km} \mathrm{~s}^{-1}\right)$ as well as the correct depth to the top of that contour. The primary advantage of the joint inversion is that it partially recovers velocity structure at depths where we have no ray coverage $(>7 \mathrm{~km})$. The joint inversion recovers the circular gravity anomaly much better than the traveltime inversion in terms of shape, extent and absolute values (Figure 8d). Because of the smoothing inherent to the inversion, velocities and densities are underestimated in the deeper section of the HVZ $(Z=5-15 \mathrm{~km})$, 


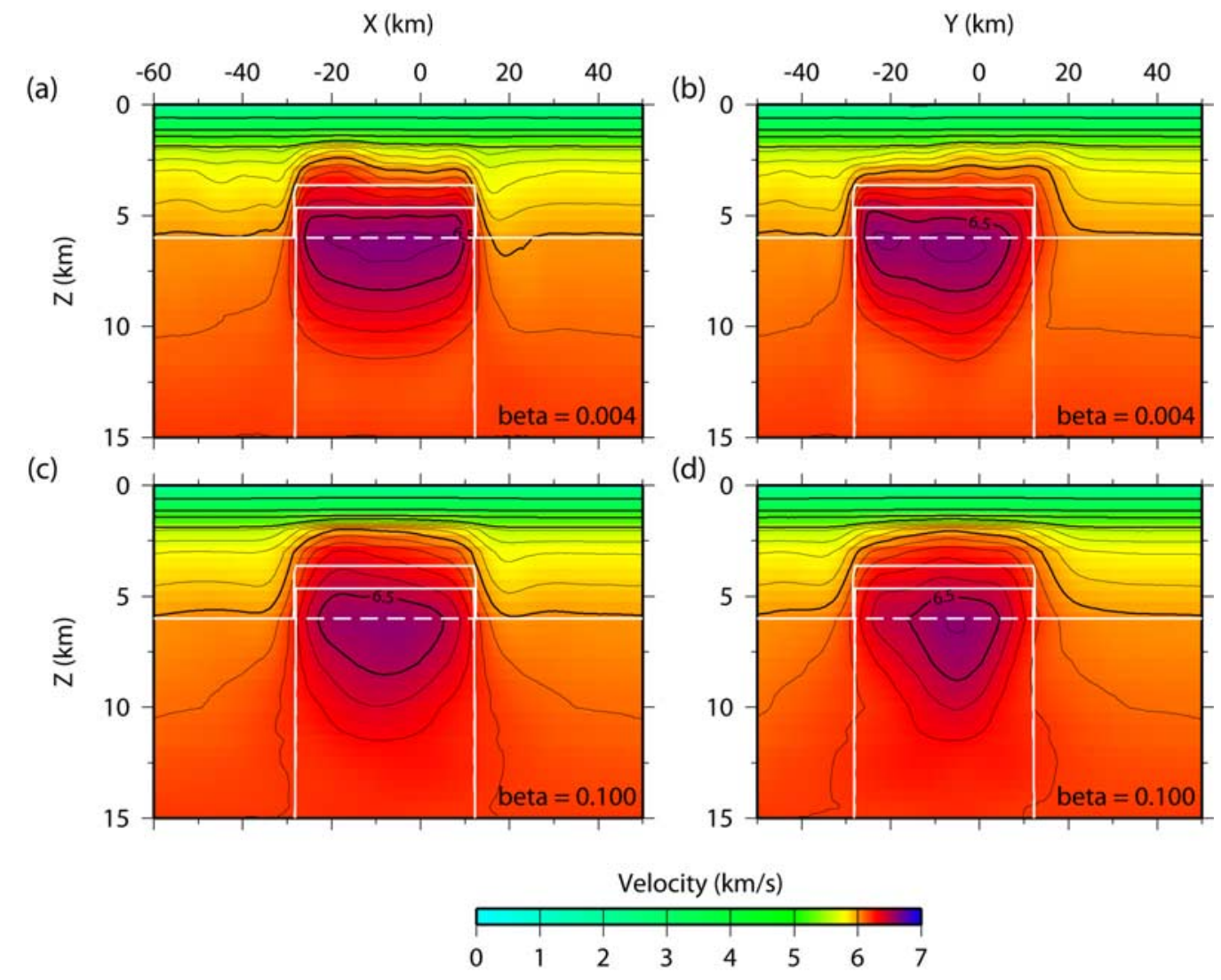

Figure 10. Inversion results of the synthetic traveltime data from the flat-topped test model in Figures 6a and $6 \mathrm{~b}$ for the 1996 and 2005 experimental geometries and the joint inversion. (a, b) Using a value of 0.004 for $\beta$ results in a good traveltime fit and bad gravity fit, whereas (c, d) using a value of 0.1 for $\beta$ results in over fitting the gravity data and not fitting the traveltime data well. Slices are at $Y=-8 \mathrm{~km}$ and $X=-8 \mathrm{~km}$. Thick black contours are shown every $1 \mathrm{~km} \mathrm{~s}^{-1}$, and thin black contours are shown every $0.1 \mathrm{~km} \mathrm{~s}^{-1}$. For comparison, the test model is indicated by solid $\left(6.0\right.$ and $\left.6.5 \mathrm{~km} \mathrm{~s}^{-1}\right)$ and dashed $\left(6.6 \mathrm{~km} \mathrm{~s}^{-1}\right)$ white contours.

whereas they are overestimated just above the HVZ $(Z<$ $3.5 \mathrm{~km}$ ). These findings need to be taken into consideration when we interpret the results of the inversion of the observed data. The total density contrast is underestimated. When we use the results of the joint inversion, $86 \%$ of the gravity anomaly is reproduced, compared to only $36 \%$ when we use the traveltime inversion.

\subsection{Synthetic Tests: Shape of Top of HVZ}

[37] After testing and optimizing the performance of the joint inversion using a test model with a flat-topped HVZ (as proposed by Hildebrand et al. [1998, 2003]), two more test models were created: one with a concave-downward or dome-shaped top (Figure 6c) and one with a concave-upward or cup-shaped top (as proposed by Morgan et al. [2000, 2002a]) (Figure 6d). The results (Figure 11) are very similar to those from the flat-topped test model. The FAST traveltime inversion performs very well with regard to recovering the correct shape and extent of the top of the HVZ, with the exception of a small artifact in the S part of the N-S profile, resulting in a $6.0 \mathrm{~km} \mathrm{~s}^{-1}$ contour that is too shallow with respect to the test model around $Y=10 \mathrm{~km}$ (Figures 11a, 11b, $11 \mathrm{e}$, and 11f). The joint inversion does not perform as well with regard to recovering the correct extent of the top of the
HVZ, but we can still distinguish between the different shapes, i.e., flat, concave-upward and concave-downward. The major advantage of the joint inversion lies in recovering velocity structure at depths where there is no ray coverage (Figures 11c, 11d, 11g, and 11h).

\section{Results From Observed Data}

[38] Using the optimum inversion parameters determined from the synthetic tests, we have performed both traveltime and joint traveltime and gravity inversions of the observed data. The final velocity models were obtained after 8 iterations. For the best model from the FAST traveltime inversion (Figures 12a and 13a), $\mathrm{RMS}_{t}$ decreased from 166 to $73 \mathrm{~ms}$ and $\chi_{t}^{2}$ decreased from 7.2 to 1.2 . For the best model from the joint inversion (Figures 12b and 13b), $\mathrm{RMS}_{t}$ and $\mathrm{RMS}_{g}$ decreased from 166 to $71 \mathrm{~ms}$ and from 59 to $8 \mathrm{gu}$, $\chi_{t}^{2}$ decreased from 7.2 to 1.2 and $\chi_{g}^{2}$ from 35 to 0.5 . Comparison of the results from the joint inversion and the FAST traveltime inversion shows that in areas that contain raypaths both inversions recover a HVZ of similar velocity, shape and extent. In the joint inversion, the gravity data are being used to update deeper parts of the model. The velocity/density lows and highs are extended to greater 

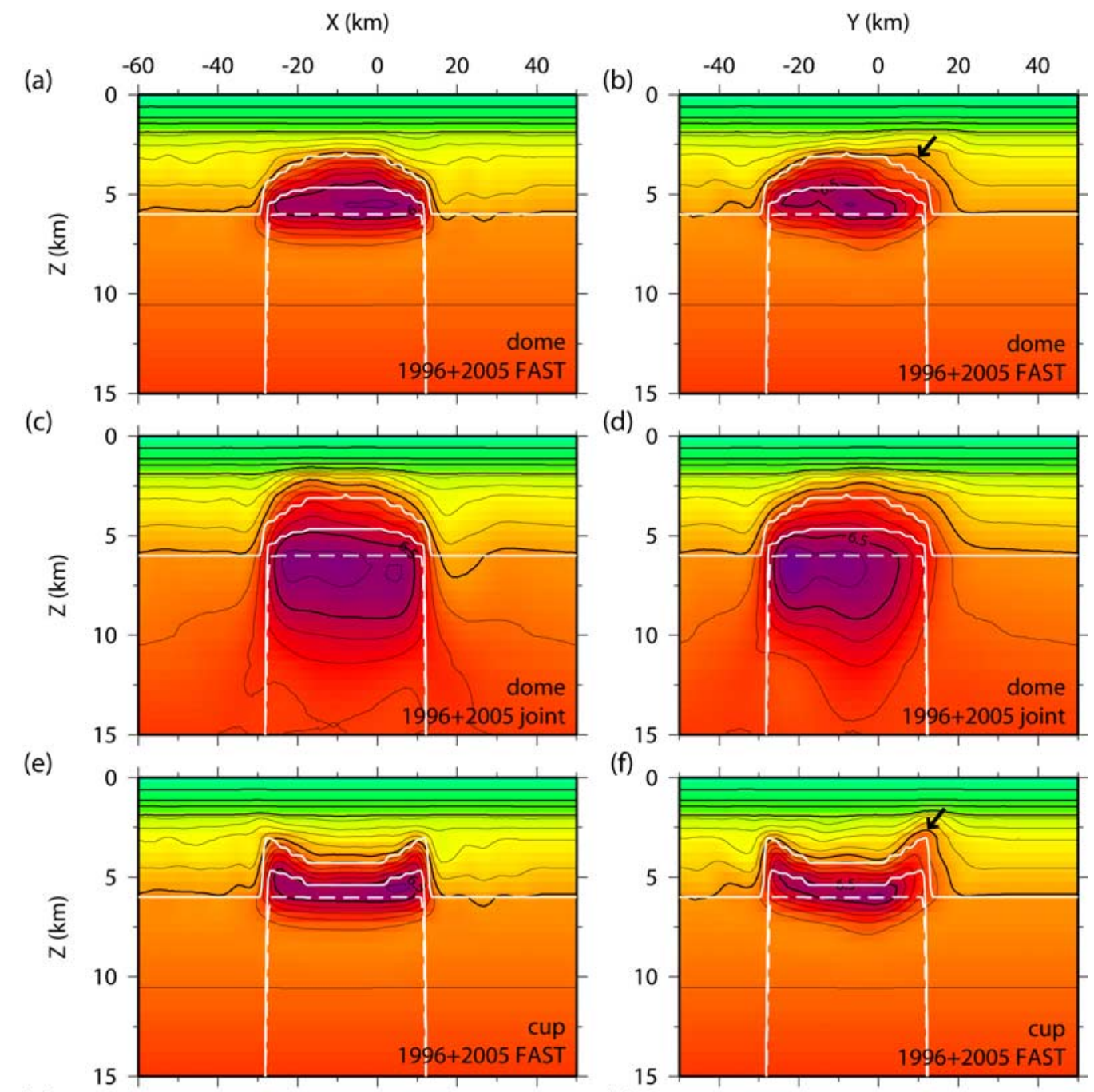

(d)
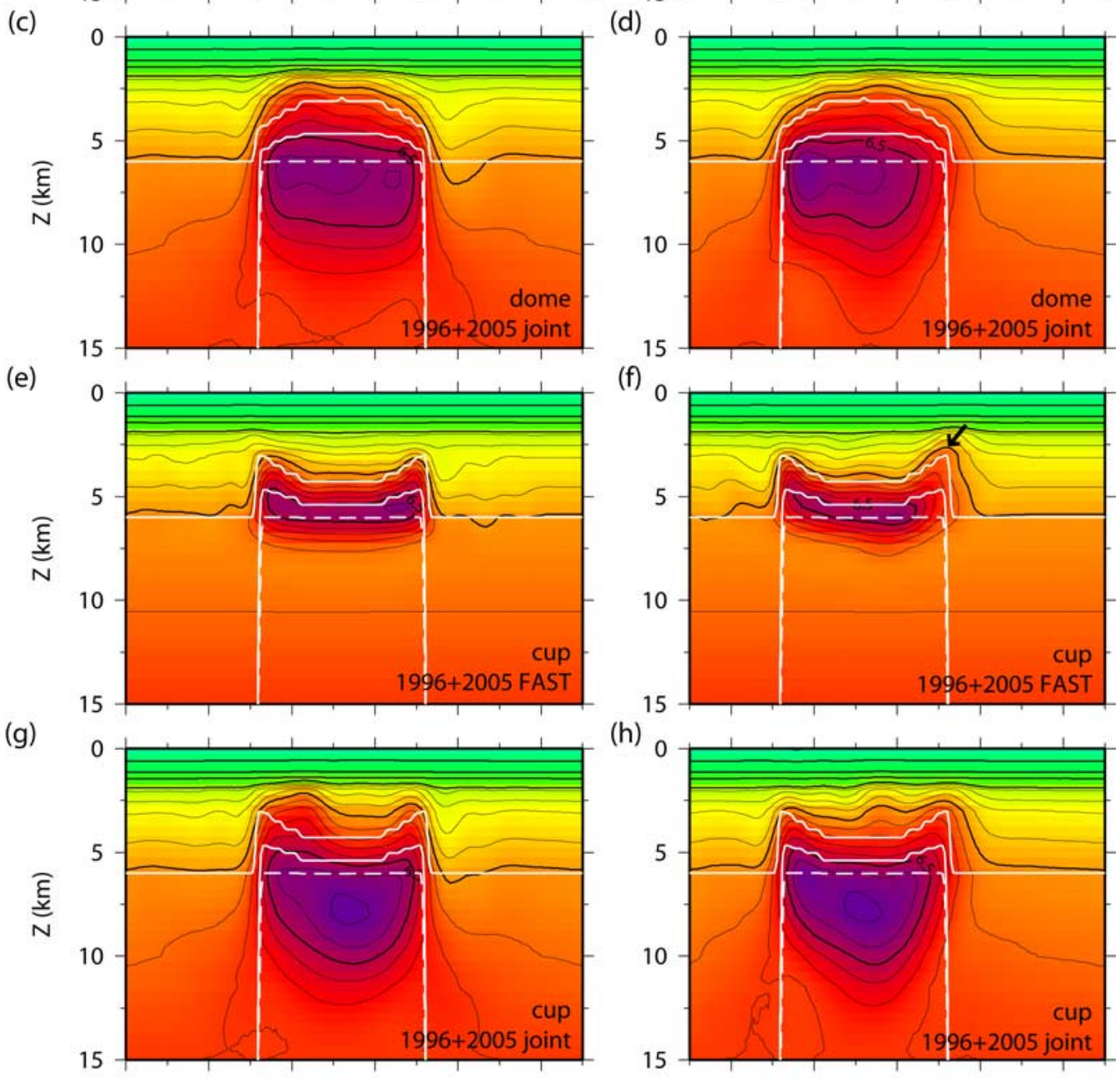

(h)
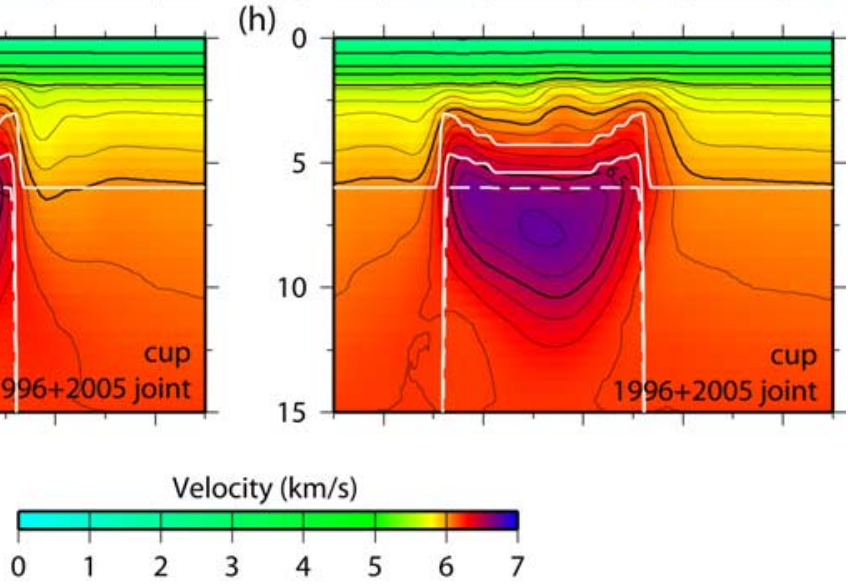

Figure 11. Inversion results of the synthetic traveltime data from the dome- and cup-shaped test models in Figures 6c and 6d using the 1996 and 2005 experimental geometries and the FAST traveltime inversion or the joint inversion. Slices are at $Y=-8 \mathrm{~km}$ and $X=-8 \mathrm{~km}$. Thick black contours are shown every $1 \mathrm{~km} \mathrm{~s}^{-1}$ and thin black contours every $0.1 \mathrm{~km} \mathrm{~s}^{-1}$. For comparison, the test model is indicated by solid $\left(6.0\right.$ and $\left.6.5 \mathrm{~km} \mathrm{~s}^{-1}\right)$ and dashed $\left(6.6 \mathrm{~km} \mathrm{~s}^{-1}\right)$ white contours. Black arrows indicate the artifact resulting from the 1996 experimental geometry when using the FAST traveltime inversion. 
(a)
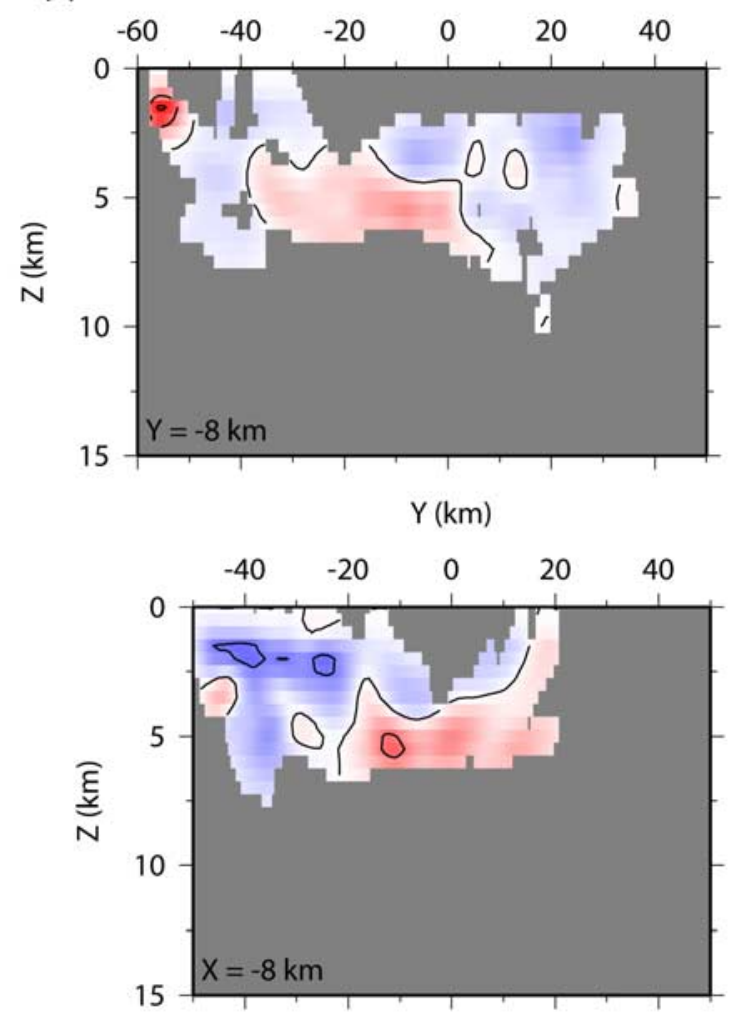

$X(\mathrm{~km})$

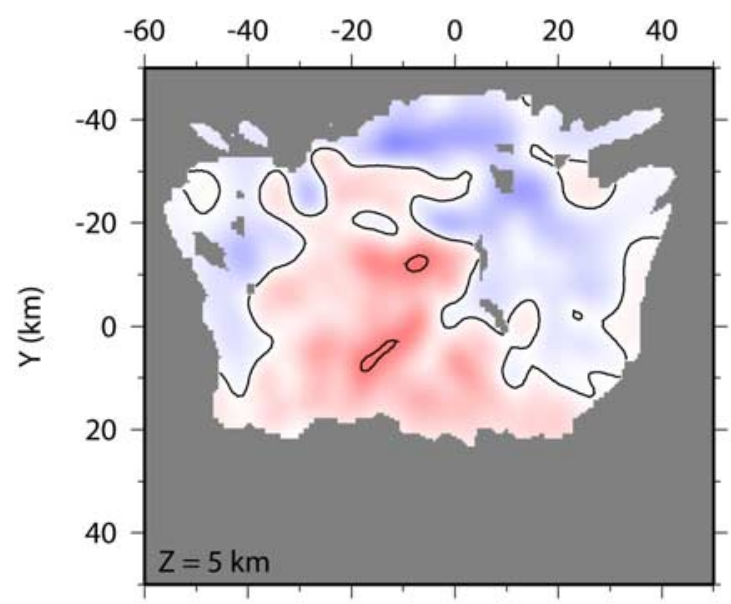

(b)

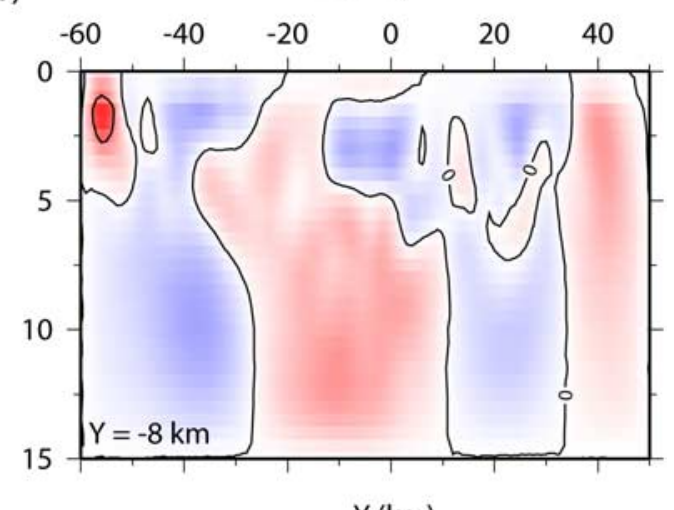

$\mathrm{Y}(\mathrm{km})$

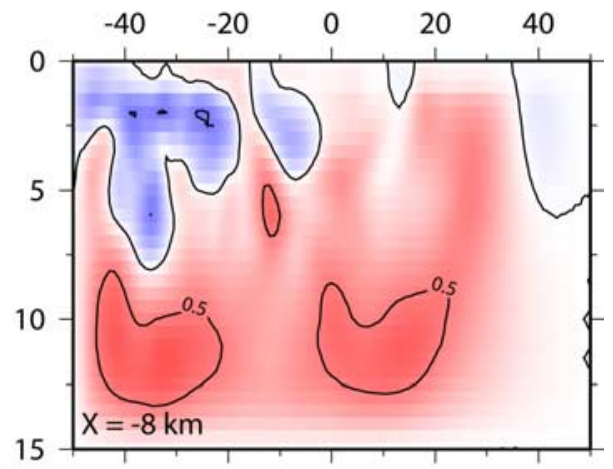

$\mathrm{X}(\mathrm{km})$

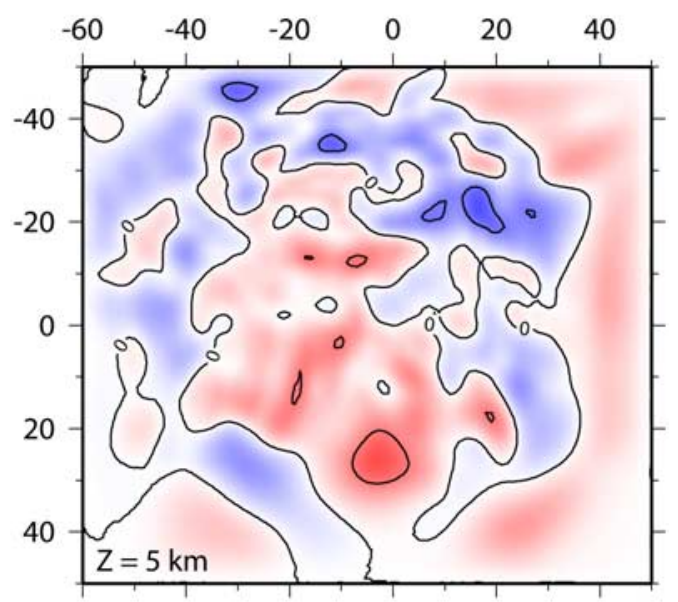

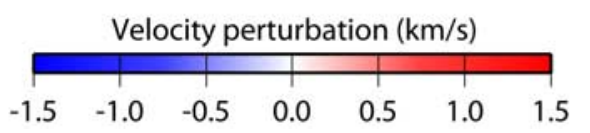

Figure 12. Velocity perturbation results of the observed traveltime data from the 1996 and 2005 experiments using (a) the FAST traveltime inversion and (b) the joint inversion. Slices are at $Y=-8 \mathrm{~km}$, $X=-8 \mathrm{~km}$ and $Z=5 \mathrm{~km}$. Contours are every $0.5 \mathrm{~km} \mathrm{~s}^{-1}$. Cells without ray coverage are masked in Figure 12a.

depths in the model to attempt to reproduce the full gravity anomaly. Where ray coverage is nonexistent or limited (see Figure 14 for ray count and Yhap [2007] and the auxiliary material of Vermeesch and Morgan [2008] for checkerboard test results), the joint inversion is controlled by the gravity data only.
[39] The results of the traveltime and joint inversion show that the top of the HVZ is not simply concave or flat, but that it has a complex 3-D shape [Vermeesch and Morgan, 2008]. This structure is unlikely to be an artifact from the inversion, as shown in the synthetic tests of the traveltime inversion (Figures $7 \mathrm{~g}, 7 \mathrm{~h}, 11 \mathrm{a}, 11 \mathrm{~b}, 11 \mathrm{e}$, and 11f), where the depth 
(a)
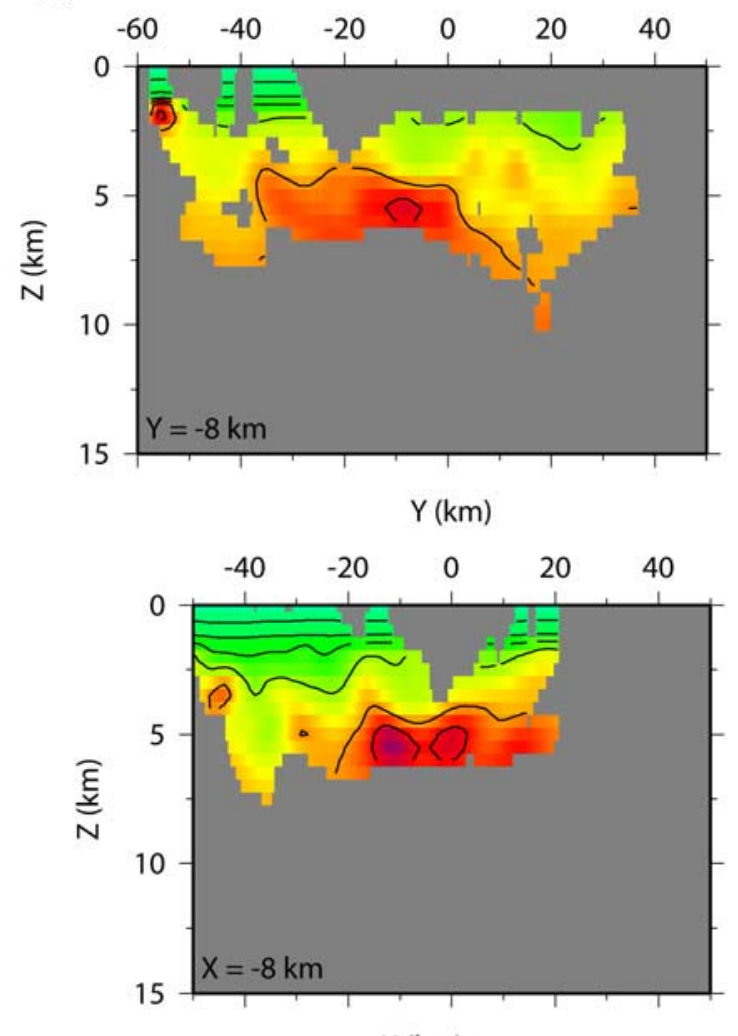

$\mathrm{X}(\mathrm{km})$

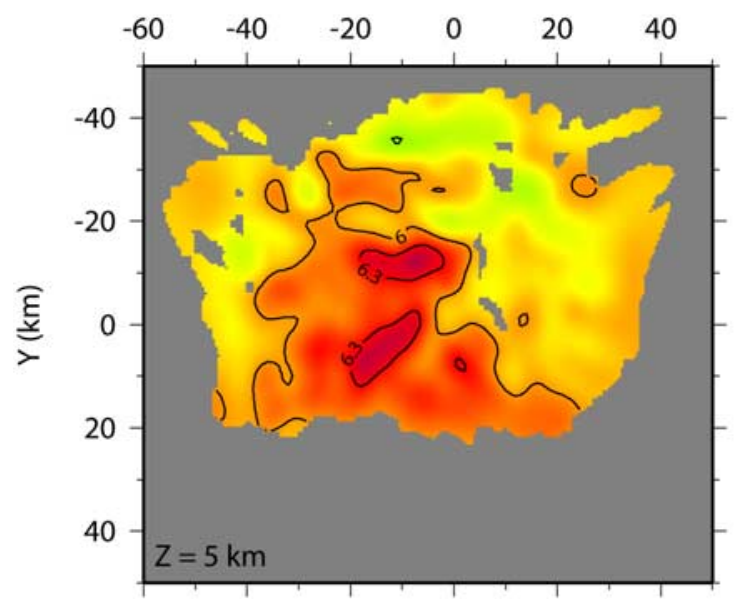

(b)

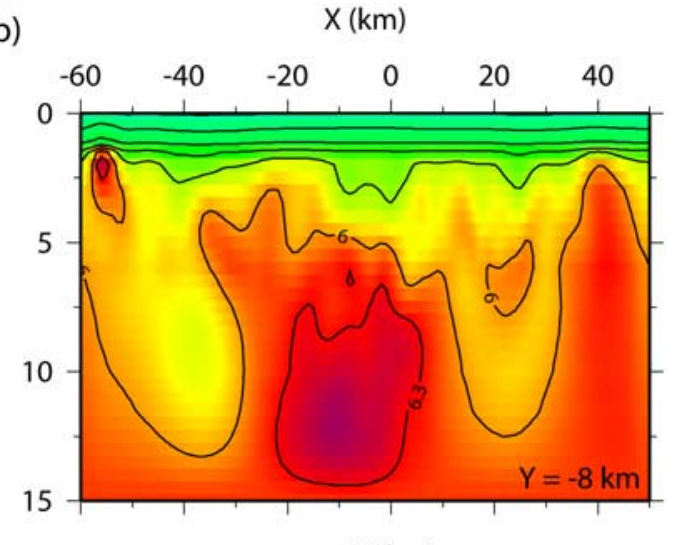

$\mathrm{Y}(\mathrm{km})$

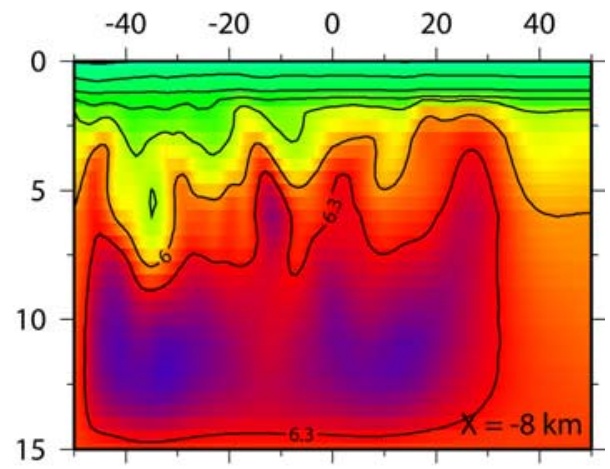

$\mathrm{X}(\mathrm{km})$

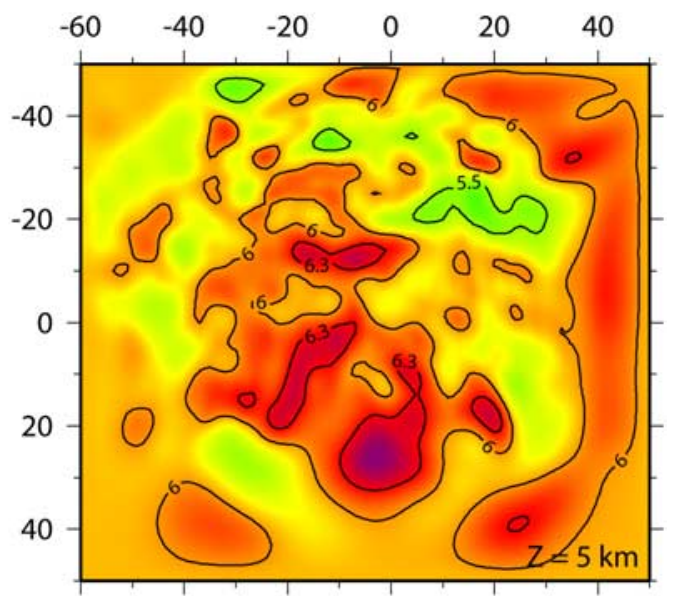

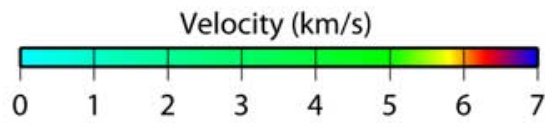

Figure 13. Inversion results of the observed traveltime data from the 1996 and 2005 experiments using (a) the FAST traveltime inversion and (b) the joint inversion. Slices are at $Y=-8 \mathrm{~km}, X=-8 \mathrm{~km}$ and $Z=5 \mathrm{~km}$. Contours are at 4.0, 4.5, 5.0, 5.5, 6.0 and $6.3 \mathrm{~km} \mathrm{~s}^{-1}$. Cells without ray coverage are masked in Figure 13a.

to the 6.0 and $6.5 \mathrm{~km} \mathrm{~s}^{-1}$ contours was recovered within $0.5 \mathrm{~km}$ for different shapes of the top of the HVZ. The synthetic tests also showed that the joint inversion did not accurately recover the depth to the top of the HVZ, although the overall shape of the top of the HVZ was preserved. Hence we favor the traveltime inverted model in all areas where the lateral resolution is good. The top of the zone of elevated velocities is thus indeed at $\sim 3 \mathrm{~km}$ depth $\pm 0.5 \mathrm{~km}$ (Figure 13a), as observed by Morgan et al. [2002a].

[40] The highest absolute velocity value in the upper part of the HVZ is $6.5 \mathrm{~km} \mathrm{~s}^{-1}$ for the joint inversion and $6.4 \mathrm{~km} \mathrm{~s}^{-1}$ for the traveltime inversion. Using our experience 

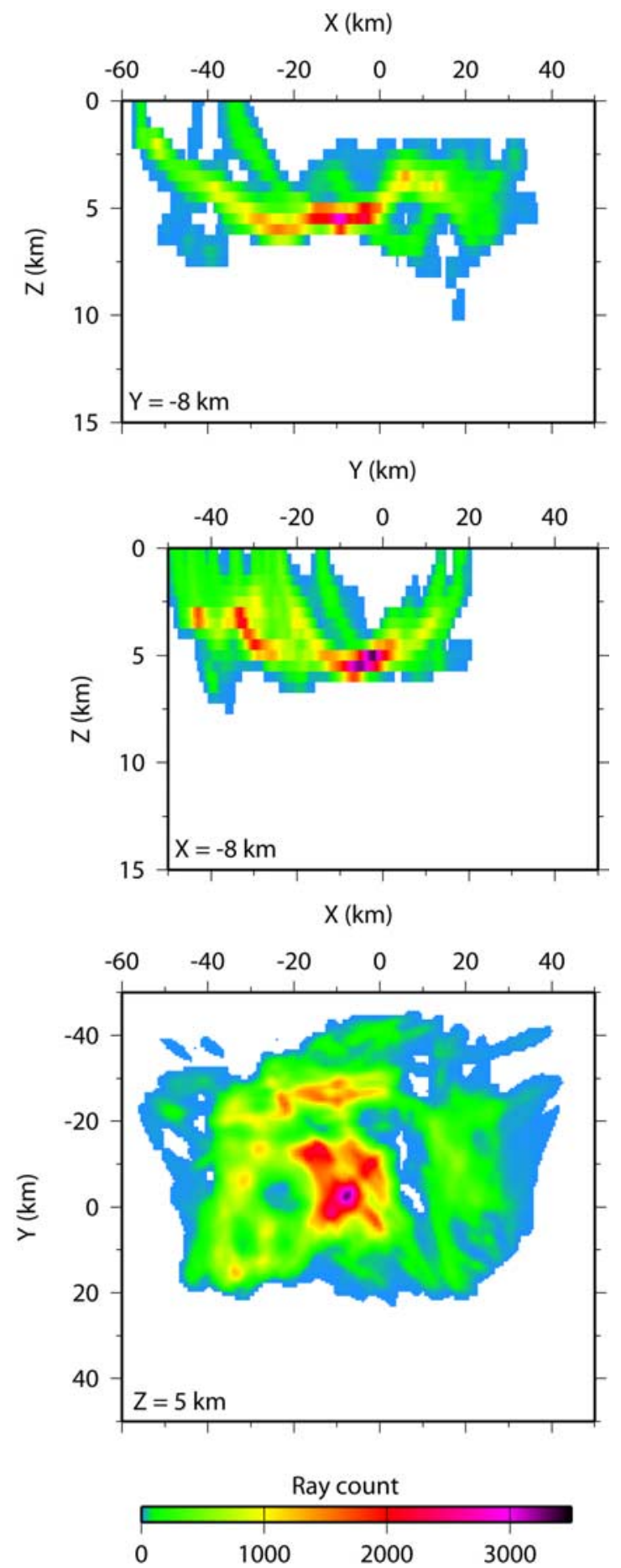

Figure 14. Ray count of the observed traveltime data from the 1996 and 2005 experiments using the FAST traveltime inversion. Slices are at $Y=-8 \mathrm{~km}, X=-8 \mathrm{~km}$, and $Z=5 \mathrm{~km}$.

with the synthetic model, we assert that the top of the central uplift at Chicxulub contains velocities between 6.0 and $6.5 \mathrm{~km} \mathrm{~s}^{-1}$. The HVZ is thus likely to contain a significantly higher velocity than first interpreted by Morgan et al. [2000, 2002a] $\left(>6.2 \mathrm{~km} \mathrm{~s}^{-1}\right)$ and by Christeson et al. [2001] $\left(>6.3 \mathrm{~km} \mathrm{~s}^{-1}\right.$ at $\left.\sim 6 \mathrm{~km} \mathrm{depth}\right)$.
[41] The traveltime inversion recovers $32 \%$ of the observed gravity anomaly associated with the central uplift or HVZ (Figure 3c), whereas the joint inversion recovers $75 \%$ (Figure $3 \mathrm{~d}$ ).

\section{Discussion}

[42] In the synthetic tests, the joint inversion did not accurately recover the depth to the top of the uplift (i.e., the HVZ). Instead, the $6.0 \mathrm{~km} \mathrm{~s}^{-1}$ contour was too shallow and the top of the $6.5 \mathrm{~km} \mathrm{~s}^{-1}$ contour was too deep compared to the test model. This resulted in velocities that were too high between 1 and $4 \mathrm{~km}$ depth, and too low below $4 \mathrm{~km}$. All geophysical models are nonunique, and a range of models fit the data equally well. The nonuniqueness of gravity modeling has been illustrated here, where the gravity anomaly is modeled with a less dense stratigraphic uplift that lies closer to the surface, or a more deeply buried but denser uplift, and a stratigraphic uplift that has gradual changes in density. The same is true for velocity modeling. It can be difficult to distinguish between a gradual and abrupt velocity step. Here we have demonstrated that a traveltime inversion, and a combined traveltime and gravity inversion, are successful at resolving subsurface structure, and that the two inversions complement each other. One particular aspect of the FAST inversion scheme is that it is regularized to favor smoothed or minimally perturbed models, resulting in final models that are smoothed horizontally and vertically. However, the 3-D traveltime inversion was able to recover the correct location in the uppermost central crater where ray coverage was high, and the combined inversion was able to partially resolve deeper subsurface structure. Therefore the traveltime inverted model was favored in its recovery of the depth of the 6.0 to $6.3 \mathrm{~km} \mathrm{~s}^{-1}$ contours in all areas where the lateral resolution [Yhap, 2007; Vermeesch and Morgan, 2008, auxiliary material] was good.

[43] In the joint inversion of the synthetic data, the calculated gravity anomaly range was $86 \%$ of the observed range, whereas in the joint inversion of the observed data it was $75 \%$, which is still significantly higher than $32 \%$ in the traveltime inversion of the observed data. One of the reasons that the extreme gravity anomalies are not recovered is probably because the inversion underestimates deeper velocity and density highs, as seen in the synthetic tests. Moreover, the model only extends to $15 \mathrm{~km}$ depth, whereas the gravity signature is believed to originate also from parts deeper than that, assuming that the middle of the central uplift has uplifted by $18-20 \mathrm{~km}$ according to scaling laws for the stratigraphic uplift [Grieve et al., 1981].

[44] A linear relationship was derived between slowness and density to allow the calculation of gravity values at the surface from a 3-D velocity model. This relationship was derived from the results of a series of ultrasonic measurements and calculations on samples from the Yax-1 and Y-6 core in the Chicxulub crater. To test the influence of the variation (deviation from the mean) in the linear relationship between slowness and density, two more inversions were carried out using linear regression curves corresponding to densities that were $10 \%$ higher and lower than the calculated mean. It was observed that a $10 \%$ increase or decrease over the whole relationship between slowness and density does not influence the shape and structure of the velocity model, 
but results in a $0.2 \mathrm{~km} \mathrm{~s}^{-1}$ or $2 \%$ uncertainty in the highest acquired absolute velocity. All ultrasonic velocity data derived from samples from within the basin fall within the $\pm 8 \%$ boundaries of the derived linear regression curve. The largest uncertainty of the validity of this velocitydensity or slowness-density relationship for lithologies in the central Chicxulub crater lies in the fact that we are not certain about the lithology of the high-velocity zone interpreted as central uplift. The data calculated from the basement clasts in the Yax-1 and Y-6 impact breccia fall within $13 \%$ of the linear relationship, but these clasts only come from a maximum of $8-11 \mathrm{~km}$ depth (see scaling laws for excavation [Melosh, 1989]), whereas the middle of the central uplift is estimated to have uplifted by $18-20 \mathrm{~km}$ assuming scaling laws are appropriate for larger impact craters [Grieve et al., 1981]. Considering all the data available, this linear regression curve is the best estimate to date of the relationship between slowness and density in the central part of the Chicxulub crater.

\section{Conclusions}

[45] A combined traveltime and gravity inversion has been developed, and has been shown to be a useful tool in determining subsurface structure. The 3-D inversion scheme uses a standard least squares, regularized iterative linearized approach, which relies on forward modeling algorithms for calculating gravity responses and seismic traveltimes. The presented scheme has been integrated in the existing and widely used First-Arrival Seismic Tomography (FAST) program package. Synthetic tests have indicated that it is important to optimize the joint inversion prior to applying it to observed data, and that experimental geometry has an important control on the model resolution, as indicated by the artifact resulting from the irregular geometry of the 1996 experiment. The experience gained through our synthetic tests have guided our inversions of the observed data, and allowed Vermeesch and Morgan [2008] to more confidently interpret central crater structure at Chicxulub.

[46] Acknowledgments. Both the 1996 and 2005 experiments were jointly funded by the Natural Environment Research Council (NERC) and the National Science Foundation (NSF). We thank Anneka Smith for supplying her traveltime picks and Chantelle Yhap for providing her checkerboard test results. Manuscript support provided by Jackson School of Geosciences and Geology Foundation at UT Austin. UTIG contribution 2051. IARC contribution 2008-1055.

\section{References}

Afnimar, K. Koketsu, and K. Nakagawa (2002), Joint inversion of refraction and gravity data for the three-dimensional topography of a sedimentbasement interface, Geophys. J. Int., 151(1), 243-254.

Bray, V. J., G. S. Collins, J. V. Morgan, and P. M. Schenk (2007), The effect of target properties on impact crater morphology-Comparison of craters on icy and silicate bodies, paper presented at Bridging the Gap II, Can. Space Agency, Montreal, Canada.

Christeson, G. L., R. T. Buffler, and Y. Nakamura (1999), Upper crustal structure of the Chicxulub impact crater from wide-angle ocean bottom seismograph data, in Large Meteorite Impacts and Planetary Evolution II, edited by B. O. Dressler and V. L. Sharpton, Spec. Pap. Geol. Soc. Am., 339, 291-298.

Christeson, G. L., Y. Nakamura, R. T. Buffler, J. V. Morgan, and M. R. Warner (2001), Deep crustal structure of the Chicxulub impact crater, J. Geophys. Res., 106, 21,751-21,769.

Collins, G. S., H. J. Melosh, J. V. Morgan, and M. R. Warner (2002), Hydrocode simulations of Chicxulub crater collapse and peak-ring formation, Icarus, 157, 24-33.
Collins, G. S., J. Morgan, P. Barton, G. L. Christeson, S. Gulick, J. Urrutia, M. Warner, and K. Wunnemann (2008), Dynamic modeling suggests terrace zone asymmetry in the Chicxulub crater is caused by target heterogeneity, Earth Planet. Sci. Lett., 270(3-4), 221-230.

Golizdra, G. Y. (1980), Combined interpretation of gravity and seismic evidence-Formulation of problems, Izv. Akad. Nauk SSSR Fiz. Zemli(7), $95-100$.

Grieve, R. A. F., P. B. Robertson, and M. R. Dence (1981), Constraints on the formation of ring impact structures, based on terrestrial data, in Proceedings of the Conference on Multi-Ring Basins-Formation and Evolution, Houston, Texas, November 10-12, 1980, edited by P. H. Schultz and B. Merrill, Proc. Lunar Planet. Sci., 12A, 37-57.

Gulick, S. P. S., et al. (2008), Importance of pre-impact crustal structure for the asymmetry of the Chicxulub impact crater, Nature Geosci., 1, 131135, doi:10.1038/ngeo103.

Hildebrand, A., et al. (1998), Mapping Chicxulub crater structure with gravity and seismic reflection data, in Meteorites-Flux with Time and Impact Effects, edited by G. J. H. McCall et al., Geol. Soc. Spec. Publ., 140, 153-173.

Hildebrand, A. R., J. D. Millar, M. Pilkington, and D. C. Lawton (2003), Three dimensional gravity field modeling of the Chicxulub impact crater, Geophys. Res. Abstr., 5, 14,414.

Hole, J. A., and B. C. Zelt (1995), Three-dimensional finite-difference reflection times, Geophys. J. Int., 121, 427-434.

Jegen, M. D., B. Heincke, and R. Hobbs (2006), Joint inversion of MT, gravity, and seismic data applied to sub-basalt imaging, paper presented at 76th SEG Meeting, New Orleans, La.

Lees, J. M., and J. C. Vandecar (1991), Seismic tomography constrained by Bouguer gravity-anomalies-Applications in western Washington, Pure Appl. Geophys., 135(1), 31-52.

Lines, L. R., A. K. Schultz, and S. Treitel (1988), Cooperative inversion of geophysical-data, Geophysics, 53(1), 8-20.

Ludwig, W. J., J. E. Nafe, and C. L. Drake (1970), Seismic refraction, in The Sea, vol. 4, edited by A. E. Maxwell, pp. 53-84, Wiley-Interscience, New York.

Melosh, H. J. (1989), Impact Cratering: A Geologic Process, Oxford Univ. Press, New York.

Morgan, J. V., M. R. Warner, G. S. Collins, H. J. Melosh, and G. L. Christeson (2000), Peak-ring formation in large impact craters: Geophysical constraints from Chicxulub, Earth Planet. Sci. Lett., 183, 347-354.

Morgan, J. V., G. L. Christeson, and C. A. Zelt (2002a), Testing the resolution of a $3 \mathrm{D}$ velocity tomogram accross the Chicxulub crater, Tectonophysics, $355,215-226$.

Morgan, J. V., M. R. Warner, and R. A. F. Grieve (2002b), Geophysical constraints on the size and structure of the Chicxulub impact crater, in Catastrophic Events and Mass Extinctions: Impacts and Beyond, edited by C. Koeberl and K. G. MacLeod, Spec. Pap. Geol. Soc. Am., 356, 39-46.

Nielsen, L., and B. H. Jacobsen (2000), Integrated gravity and wide-angle seismic inversion for two-dimensional crustal modelling, Geophys. J. Int., 140(1), 222-232.

Paige, C. C., and M. A. Saunders (1982), LSQR: An algorithm for sparse linear equations and sparse least squares, Trans. Math. Software, 8(1), $43-71$.

Pilkington, M., and A. R. Hildebrand (2000), Three-dimensional magnetic imaging of the Chicxulub crater, J. Geophys. Res., 105(B10), 23,47923,491.

Pilkington, M., A. Hildebrand, and C. Ortiz-Aleman (1994), Gravity and magnetic field modelling and structure of the Chicxulub crater, Mexico, J. Geophys. Res., 99, 13,147-13,162.

Roy, L., M. K. Sen, K. McIntosh, P. L. Stoffa, and Y. Nakamura (2005), Joint inversion of first arrival seismic travel-time and gravity data, J. Geophys. Eng., 2(3), 277-289.

Scales, J. A., P. Docherty, and A. Gersztenkorn (1990), Regularisation of nonlinear inverse problems: Imaging the near-surface weathering layer, Inverse Problems, 6(1), 115-131.

Senft, L. E., and S. T. Stewart (2007), Modeling impact cratering in layered surfaces, J. Geophys. Res., 112, E11002, doi:10.1029/2007JE002894.

Stewart, S. T., and L. E. Senft (2007), Frictional melting and complex crater collapse, paper presented at Bridging the Gap II, Can. Space Agency, Montreal, Canada.

Styles, E. (2006), Chicxulub: An analysis of new gravity data, M.S. thesis, Imp. Coll. London, London.

Tikhotsky, S., and U. Achauer (2008), Inversion of controlled-source seismic tomography and gravity data with the self-adaptive wavelet parametrization of velocities and interfaces, Geophys. J. Int., 172(2), 619-630.

Tondi, R., R. de Franco, and R. Barzaghi (2000), Sequential integrated inversion of refraction and wide-angle reflection traveltimes and gravity data for two-dimensional velocity structures, Geophys. J. Int., 141(3), $679-698$

Vermeesch, P. M. (2006), Geophysical modelling of the Chicxulub crater, Ph.D. thesis, Imp. Coll. London, London. 
Vermeesch, P. M., and J. V. Morgan (2004), Chicxulub central crater structure: Initial results from physical property measurements and combined velocity and gravity modeling, Meteorit. Planet. Sci., 39(7), 1019-1034. Vermeesch, P. M., and J. V. Morgan (2008), Structural uplift beneath the Chicxulub impact structure, J. Geophys. Res., 113, B07103, doi:10.1029/ 2007JB005393

Vidale, J. E. (1988), Finite-difference calculation of travel times, Bull. Seismol. Soc. Am., 78(6), 2062-2076.

Vidale, J. E. (1990), Finite-difference calculation of traveltimes in three dimensions, Geophysics, 55(5), 521-526.

Wang, T. K., S. F. Lin, C. S. Liu, and C. S. Wang (2004), Crustal structure of the southernmost Ryukyu subduction zone: OBS, MCS and gravity modelling, Geophys. J. Int., 157(1), 147-163.

Wünnemann, K., J. Morgan, and H. Jödicke (2005), Is Ries crater typical for its size? An analysis based upon old and new geophysical data and numerical modeling, in Large Meteorite Impacts III, edited by T. Kenkmann, F. Hrz, and A. Deutsch, Spec. Pap. Geol. Soc. Am., 384, 67-83.

Yhap, C. (2007), Stratigraphic uplift beneath the Chicxulub impact crater: Resolution testing, M.S. thesis, Imp. Coll. London, London.
Zelt, C. A., and P. J. Barton (1998), Three-dimensional seismic refraction tomography: A comparison of two methods applied to data from the Faroe Basin, J. Geophys. Res., 103, 7187-7210

Zelt, C. A., A. Azara, and A. Levander (2006), 3-D seismic refraction traveltime tomography at a shallow groundwater contamination site, Geophysics, 71, H67-H78.

P. J. Barton and A. Surendra, Department of Earth Sciences, University of Cambridge, Madingley Road, Cambridge CB3 0EZ, UK.

G. L. Christeson, Institute for Geophysics, University of Texas at Austin, Building 196, 10100 Burnet Road, Austin, TX 78758-4445, USA.

J. V. Morgan, Department of Earth Science and Engineering, Imperial College London, South Kensington Campus, London SW7 2AZ, UK

P. M. Vermeesch, School of Ocean and Earth Sciences, National Oceanography Centre, Southampton University, Waterfront Campus, European Way, Southampton SO14 3ZH, UK. (p.vermeesch@soton.ac.uk) 